Research Article

\title{
Frequency and Vibration Characteristics of High-Speed Gear-Rotor-Bearing System with Tooth Root Crack considering Compound Dynamic Backlash
}

\author{
Jie Liu $(\mathbb{D}$, Weiqiang Zhao $\mathbb{D}$, and Weiwei Liu $(\mathbb{D}$ \\ School of Mechanical Engineering, Shenyang University of Technology, Shenyang 110870, China \\ Correspondence should be addressed to Weiwei Liu; vivianliu0616@163.com
}

Received 28 May 2019; Revised 10 August 2019; Accepted 26 August 2019; Published 19 November 2019

Academic Editor: Fiorenzo A. Fazzolari

Copyright (C) 2019 Jie Liu et al. This is an open access article distributed under the Creative Commons Attribution License, which permits unrestricted use, distribution, and reproduction in any medium, provided the original work is properly cited.

\begin{abstract}
Considering the microstructure of tooth surface and the dynamic characteristics of the vibration responses, a compound dynamic backlash model is employed for the gear transmission system. Based on the fractal theory and dynamic center distance, respectively, the dynamic backlash is presented, and the potential energy method is applied to compute the timevarying meshing stiffness, including the healthy gear system and the crack fault gear system. Then, a 16-DOF coupled lateraltorsional gear-rotor-bearing transmission system with the crack fault is established. The fault characteristics in the timedomain waveform and frequency response and statistics data are described. The effect of crack on the time-varying meshing stiffness is analyzed. The vibration response of three backlash models is compared. The dynamic response of the system is explored with the increase in crack depth in detail. The results show that the fault features of countershaft are more obvious. Obvious fluctuations are presented in the time-domain waveform, and sidebands can be found in the frequency domain responses when the tooth root crack appears. The effect of compound dynamic backlash on the system is more obvious than fixed backlash and backlash with changing center distance. The vibration displacement along meshing direction and dynamic meshing force increases with the increase in crack depth. Backlash and variation of center distance show different tendencies with increasing crack depth under different rotational speeds. Amplitude of the sidebands increases with crack depth increasing. The amplitude of multiplication frequency of rotational frequency has an obvious variation with growing crack depth. The sidebands of the multiplication frequency of meshing frequency show more details on the system with complex backlash and crack fault.
\end{abstract}

\section{Introduction}

The gear transmission systems are widely used in many machinery fields, which are employed for transmitting power and changing speed. The steady operation is a necessary condition for the gear system. Therefore, the mechanism and dynamic characteristics of gear failure are a major subject in the dynamic field.

The gearbox failure is closely related to gear tooth, including spalling, pitting, crack, and broken tooth, which potentially lead to a complete damage. In order to clearly detect and diagnose in the gear transmission system, the vibration responses and fault features of the gear transmission system with fault are developed [1-3].
The typical kinds of damage are crack failure and spalling failure. The vibration responses of the gear system are closely related to the time-varying meshing stiffness (TVMS) of the gear pair. Yang and Lin [4] calculated TVMS by the potential energy method considering axial compressive energy, Hertzian energy, and bending energy. Tian [5] further investigated TVMS of a gear pair with crack. Govind et al. [6] studied TVMS, crack propagation behaviour, and the vibration responses of spur gear. Chen et al. [7] presented two improved calculation models for gear tooth fillet-foundation stiffness. When a gear pair appeared a large crack length, the computational accuracy of the two models was compared. Chen and Shao [8] developed a gear pair meshing stiffness calculation method 
considering tooth profile modification and tooth root crack.

Many outstanding scholars have made great contributions to the research of healthy gear system. Zhou et al. [9] presented a coupled lateral-torsional 16-DOF gearrotor-bearing system considering piecewise periodic stiffness, friction, and eccentricity, and the motion states and frequency variations were analyzed in detail. In addition, the backlash is an important factor to ensure smooth and reliable operation. Chen et al. [10] investigated the dynamic backlash with the fractal feature and the effect of the dynamic backlash on the 2-DOF gear system. Li et al. [11] researched TVMS that was affected by tooth profile changes and developed bifurcation characteristics of the gear system. Xiang and Gao [12] calculated the differential equation of the gear transmission model with dynamic friction, TVMS, and dynamic backlash on the basis of the 4th order Runge-Kutta method and observed the effect of dynamic backlash and gear eccentricity under different rotational speeds.

Many scholars had made a mountain of work for the gearbox with crack fault. Saxena et al. [13] studied the influences of the meshing stiffness and damping on the flexible rotor-shaft system. They explored vibration responses and frequency characteristics in detail. Mohammed and Rantatalo [14] established a 6-DOF dynamic gear model to study the natural frequency and time-frequency with different crack sizes. Saeed et al. [15] researched vibration responses in the presence of single- and multi-tooth simultaneous crack using the finite element method (FEM). Ma et al. [16] established a perforated gear system with different degree cracks. The gear crack propagation paths, frequency components, and frequency values were analyzed in detail. Ma et al. [17] built a meshing stiffness model for a cracked gear system, and the influences of the crack depth and initial position were analyzed by FEM. Chen et al. [18] presented a meshing stiffness calculation method for the nonuniform tooth root crack along the tooth width. The meshing stiffness and vibration response calculated by three different algorithms were compared. Ma and Chen [19] established a 4DOF gear system to investigate the dynamic characteristics and vibration responses with local failure and explore the failure mechanism. Hu et al. [20] presented a finite element node dynamic model for gear with crack. The RMS (rootmean-square) of the gear system parameters, vibration waveform, and frequency spectra were analyzed. Chen and Shao [21] investigated the effect of crack on a planetary gear system. Liu et al. [22] studied vibration characteristics of the planetary gear system when sun gear appeared a tooth root crack.

For the research of crack, some scientists devoted to establish a simple gear model, such as simplifying backlash as a fix value, employing a periodic meshing stiffness, and establishing a few-DOF model. In this paper, a 16DOF coupled lateral-torsional gear-rotor-bearing transmission system considering compound-type dynamic backlash, TVMS, eccentricity, and friction force is established. The compound dynamic backlash on the basis of the microstructure characteristics and vibration features is defined. TVMS is calculated by the potential energy method. This complex model is employed for investigating the effect of crack faults and researching crack failure features. The vibration responses of the gear system are researched by analyzing influences of the rotational speed and crack depth value variation. The differential equations of motion are solved using the Runge-Kutta numerical method. The simulation results, including time-domain waveforms, frequency-domain spectra, and waterfall plots, are shown. We focus on the effect of the crack depth growing on a complex gear system. The amplitude statistics of sideband supply an effective reference for the condition monitoring and fault diagnosis of the gear-rotor-bearing system.

\section{Dynamic Model of the Gear-Rotor- Bearing System}

2.1. Lumped Mass Model of the Gear System. The lumped mass model of the gear system is consisted of input, gears, shafts, bearing, and output. This model is described in Figure 1. $O_{1}\left(x_{1}, y_{1}\right)$ and $O_{2}\left(x_{2}, y_{2}\right)$ are the centers of two gears. $G_{1}\left(x_{g 1}, y_{g 1}\right)$ and $G_{2}\left(x_{g 2}, y_{g 2}\right)$ are the barycenters of two gears. $m_{i}(i=1,2)$ are quality of gears. $J_{1}$ and $J_{2}$ represent the moments of gear inertial. $m_{b i}(i=1,2,3,4)$ represent quality of bearing. $J_{d}$ and $J_{g}$ are equivalent rotational inertia of input and output terminals. The torsional stiffness and damping of shaft are given by $k_{t i}$ and $c_{t i}(i=1,2) . k_{s i}$ and $c_{s i}$ $(i=1,2)$ are, respectively, lateral stiffness and damping. $c_{b i}$ $(i=1,2,3,4)$ are equivalent bearing damping, including $x$ direction and $y$ direction. In the $x$ and $y$ directions, $F_{x i}$ and $F_{y i}(i=1,2,3,4)$ are defined as nonlinear bearing forces. $\rho_{i}$ $(i=1,2)$ represent the eccentricity. $\varphi_{i}(i=1,2, d, g)$ are, respectively, angle displacements of gear, pinion, input, and output, and the angle displacements are composed of an angle displacement $\omega_{i} t(i=1,2)$ and microscopic displacement $\theta_{i}(t)$. According to the geometrical relationship, the equations for the displacement of gears and input/output are given by

$$
\begin{aligned}
& \varphi_{1}=\omega_{1} t+\theta_{1}, \\
& \varphi_{2}=\omega_{2} t+\theta_{2}, \\
& \varphi_{d}=\omega_{1} t+\theta_{d}, \\
& \varphi_{g}=\omega_{2} t+\theta_{g} .
\end{aligned}
$$

Because of the eccentricity of gears, the rotating geometrical centers $O_{1}\left(x_{1}, y_{1}\right)$ and $O_{2}\left(x_{2}, y_{2}\right)$ and the barycenters $G_{1}\left(x_{g 1}, y_{g 1}\right)$ and $G_{2}\left(x_{g 2}, y_{g 2}\right)$ are at different positions. The relationship equations are found as

$$
\begin{aligned}
& x_{g 1}=x_{1}+\rho_{1} \cos \varphi_{1}, \\
& y_{g 1}=y_{1}+\rho_{1} \sin \varphi_{1}, \\
& x_{g 2}=x_{2}+\rho_{2} \cos \varphi_{2}, \\
& y_{g 2}=y_{2}+\rho_{2} \sin \varphi_{2} .
\end{aligned}
$$

In the xoy plane, elastic deformation of the shafts can be determined as 


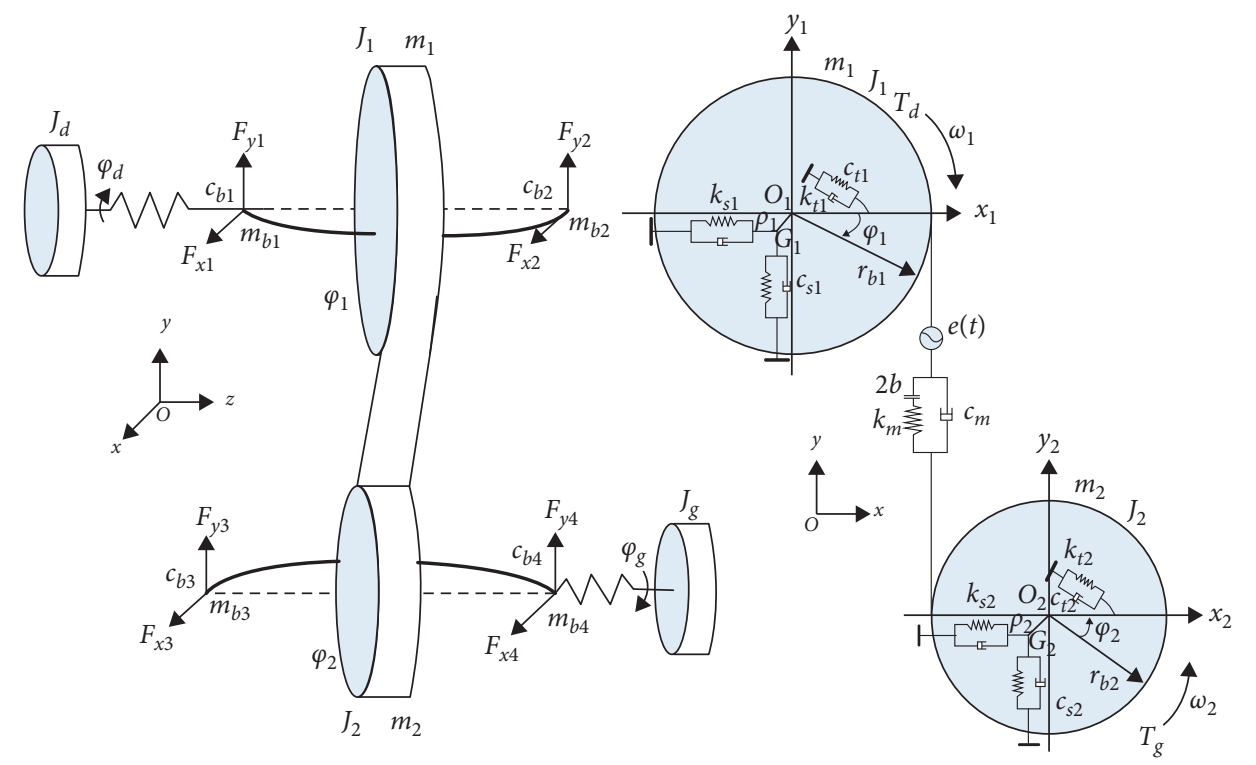

Figure 1: The gear system model.

$$
\begin{aligned}
& \delta_{x 1}=x_{1}-\xi_{1} x_{b 1}-\xi_{2} x_{b 2}, \\
& \delta_{y 1}=y_{1}-\xi_{1} y_{b 1}-\xi_{2} y_{b 2}, \\
& \delta_{x 2}=x_{2}-\xi_{3} x_{b 4}-\xi_{4} x_{b 3}, \\
& \delta_{y 2}=y_{2}-\xi_{3} y_{b 4}-\xi_{4} y_{b 3},
\end{aligned}
$$

where $\xi_{i}$ can be computed as

$$
\xi_{i}=\frac{l_{b i}}{l_{j}}, \quad i=1,2,3,4 ; j=1,2,
$$

where $l_{b i}$ represents the distances between the gear's centers and centers of bearing and $l_{j}$ is the length of shafts. The deformation between two gears along the meshing direction $\delta(t)$ is given by

$$
\begin{aligned}
\delta(t)= & \left(r_{b 1} \varphi_{1}-r_{b 2} \varphi_{2}\right)+\left(y_{g 1}-y_{g 2}\right)-e(t), \\
= & \left(r_{b 1} \theta_{1}-r_{b 2} \varphi_{2}\right)+\left(y_{1}-y_{2}+\rho_{1} \sin \varphi_{1}-\rho_{2} \sin \varphi_{2}\right) \\
& -e(t),
\end{aligned}
$$

where static transmission error $e(t)$ is caused by manufacture and assembly, and $r_{b 1}$ and $r_{b 2}$ are gear base circle radii. This error can be treated as a sinusoidal function $e(t)=$ $e_{0}+e_{r} \sin \left(\omega_{m} t+\varphi_{m}\right)$ [9], where $e_{0}$ and $e_{\mathrm{r}}$ severally represent mean and amplitude of the error, and $\varphi_{m}$ and $\omega_{m}$ are, respectively, initial phase and meshing frequency. $\omega_{m}$ meshing frequency is expressed as $\omega_{m}=2 \pi n_{1} z_{1} / 60\left(2 \pi n_{2} z_{2} / 60\right) . z_{1}$ and $z_{2}$ are the gears' teeth. $n_{1}$ and $n_{2}$ are the gears' rotating velocity.

The dynamic meshing force (DMF) $F_{m}(j=1,2)$ can be determined as

$$
F_{m}=\sum_{i=1}^{j} F_{m i}=\sum_{i=1}^{j} k_{t i} f(\delta(t))+c_{m} \dot{\delta}(t),
$$

where the state is the single-tooth meshing at $j=1$, while the state is double-tooth meshing at $j=2 . k_{t i}(i=1,2)$ and $c_{m}$ are TVMS and meshing damping, respectively. $f(\delta)$ is the backlash function in the gear system, which is given by [23]

$$
\begin{aligned}
f(\delta) & = \begin{cases}\delta(t)-(1-\psi) b_{h}(t), & \delta(t)>b_{h}(t), \\
\psi b_{h}(t), & -b_{h}(t)<\delta(t)<b_{h}(t), 0 \leq \psi \leq 1, \\
\delta(t)+(1-\psi) b_{h}(t), & \delta(t)<-b_{h}(t),\end{cases} \\
c_{m} & =2 \xi_{m} \sqrt{\frac{k_{t}}{\left(1 / m_{1}\right)+\left(1 / m_{2}\right)},}
\end{aligned}
$$

where $b_{h}(t)$ is the gear dynamic backlash and $\psi$ is a nonlinear coefficient. Meshing damping is given by $c_{m} . b_{h}(t)$ is presented in Section 2.3.

2.2. Time-Varying Meshing Stiffness for Gears with Tooth Crack. The meshing stiffness model of a gear pair with a tooth root crack was described by Tian in 2004. The energy method was used to solve the mathematical modeling problem of the gear meshing stiffness. On the basis of the research, we further investigated the gear system with a tooth root crack with time-varying meshing stiffness. The schematic graph of tooth crack is shown in Figures 2(a) and 2(b).

The potential energy of the meshing gear teeth is shown as follows [21]:

$$
\begin{aligned}
U_{b} & =\int_{0}^{d} \frac{F_{b}\left[(d-x)-F_{a} h\right]^{2}}{2 E I_{x}} d x, \\
U_{s} & =\int_{0}^{d} \frac{1.2 F_{b}^{2}}{2 \mathrm{GA}_{x}} d x, \\
U_{a} & =\int_{0}^{d} \frac{F_{a}^{2}}{2 \mathrm{EA}_{x}} d x .
\end{aligned}
$$




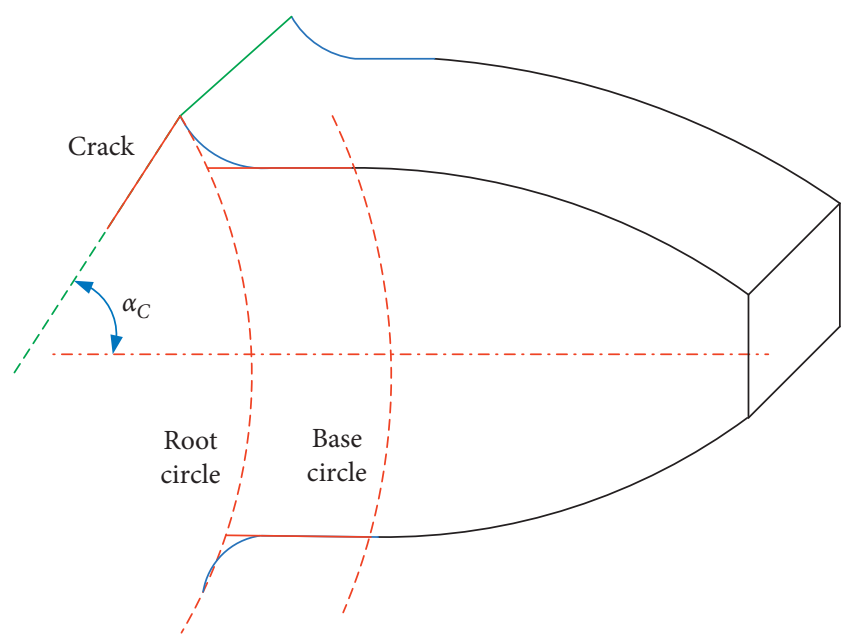

(a)

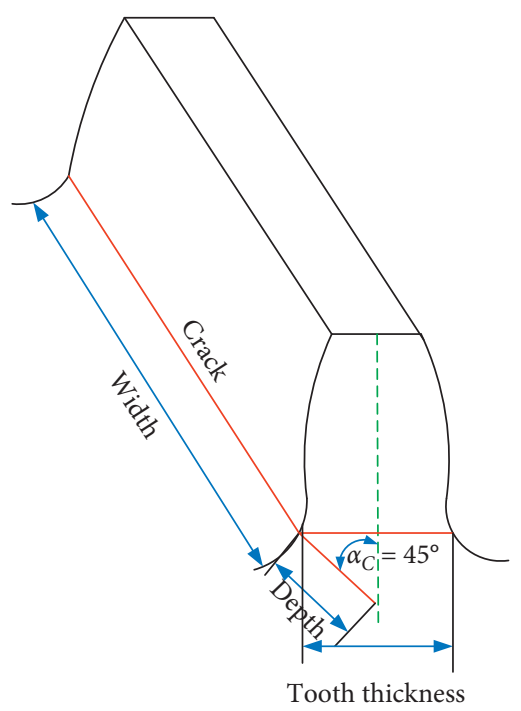

(b)

FIgURE 2: $(a, b)$ Schematic graph of tooth crack.

$I_{x}$ and $A_{x}$ are equivalent to the area moment of inertia and the area of the section, respectively [5], and $G$ represents the shear modulus. They are determined as

$$
\begin{aligned}
I_{x} & =\frac{1}{12}\left(2 h_{x}\right)^{3} L, \\
A_{x} & =\left(2 h_{x}\right) L, \\
G & =\frac{E}{2(1+v)},
\end{aligned}
$$

where $h_{x}$ is the distance between the point on the tooth's curve and the tooth's central line [5].

For the single-tooth-pair meshing process, the overall meshing stiffness for the gears with tooth crack could be given by

$$
k_{t}=\frac{1}{\left(1 / k_{h}\right)\left(+1 / k_{b 1}\right)+\left(1 / k_{s 1}\right)+\left(1 / k_{a 1}\right)+\left(1 / k_{b 2}\right)+\left(1 / k_{s 2}\right)+\left(1 / k_{a 2}\right)},
$$

where $k_{h}$ is the Hertzian contact stiffness, $k_{s}$ is the shear stiffness, $k_{b}$ is the bending stiffness, and $k_{a}$ is the axial compression stiffness. And $k_{h}$ can be given by

$$
k_{h}=\frac{\pi E L}{4\left(1-v^{2}\right)} \text {. }
$$

where $E$ is Young's modulus and $L$ is the tooth face width. $F_{f}=\mu \lambda\left(v_{S}\right) F_{m}$ represents Poisson's ratio. In addition, $k_{b}, k_{s}$, and $k_{a}$ can be expressed as

$$
\begin{aligned}
& \frac{1}{k_{b}}=\int_{-\alpha_{1}}^{\alpha_{2}} \frac{3\left\{1+\cos \alpha_{1}\left[\left(\alpha_{2}-\alpha\right) \sin \alpha-\cos \alpha\right]\right\}^{3}\left(\alpha_{2}-\alpha\right) \cos \alpha}{E\left(2 L\left[\sin \alpha+\left(\alpha_{2}-\alpha\right) \cos \alpha\right]^{3}\right)} d \alpha, \\
& \frac{1}{k_{s}}=\int_{-\alpha_{1}}^{\alpha_{2}} \frac{1 \cdot 2(1+v)\left(\alpha_{2}-\alpha\right) \cos \alpha \cos ^{2} \alpha_{1}}{E\left(L\left[\sin \alpha+\left(\alpha_{2}-\alpha\right) \cos \alpha\right]\right)} d \alpha, \\
& \frac{1}{k_{a}}=\int_{-\alpha_{1}}^{\alpha_{2}} \frac{\left(\alpha_{2}-v\right) \cos \alpha \sin ^{2} \alpha_{1}}{E\left(2 L\left[\sin \alpha+\left(\alpha_{2}-\alpha\right) \cos \alpha\right]\right)} d \alpha .
\end{aligned}
$$


For the double-tooth-pair meshing process, the overall meshing stiffness for the gears with tooth crack could be given by

$$
k_{t}=k_{t 1}+k_{t 2}=\sum_{i=1}^{2} \frac{1}{\left(1 / k_{h, i}\right)+\left(1 / k_{b 1, i}\right)+\left(1 / k_{s 1, i}\right)+\left(1 / k_{a 1, i}\right)+\left(1 / k_{b 2, i}\right)+\left(1 / k_{s 2, i}\right)+\left(1 / k_{a 2, i}\right)},
$$

where $i(i=1,2)$ are the first or second pair of meshing teeth.

When the gear pair appears a tooth root crack, $I_{x c}$ and $A_{x c}$ are expressed as

$$
\begin{aligned}
& I_{x c}= \begin{cases}\frac{1}{12}\left(h_{c}+h_{x}\right)^{3} L, & \text { if } x \leq g_{c}, \\
\frac{1}{12}\left(2 h_{x}\right)^{3} L=\frac{2}{3} h_{x}^{3} L, & \text { if } x>g_{c},\end{cases} \\
& A_{x c}= \begin{cases}\left(h_{c}+h_{x}\right) L, & \text { if } x \leq g_{c}, \\
2 h_{x} L, & \text { if } x>g_{c},\end{cases}
\end{aligned}
$$

where $h_{c}$ represents the distance between the root the crack and the central line of the tooth. The other parameters and formulas are given in $[4,5,21]$.

The overall effective meshing stiffness is given by the equations. Crack position is a tooth root of pinion. Equation (14) is input into equation (8), and then TVMS can be calculated. The time-varying meshing stiffness can be provided as shown in Figure 3.

2.3. Dynamic Backlash. In the gear mesh process, the backlash is one of the most important factors. The backlash is the distance between two tooth profiles. In order to prevent the gears from getting stuck and ensure lubrication of gears, the backlash must exist. Rough tooth surfaces are not considered as an inherent characteristic. In the section, the compound dynamic backlash model is established considering rough tooth surface and vibration characteristic of the gear system. The sketch of backlash is shown in Figure 4. The relative displacement is generated when two rough teeth surface gears mesh.

The dynamic backlash $b_{h}(t)$ is consisted of the microscopic backlash $\Delta b(t)$ and vibration variation backlash $b(t)$. In order to approximate rough tooth surfaces, the W-M fractal function is employed. The microscopic backlash $\Delta b(t)$, which represents the inherent characteristic of the rough tooth surface, can be determined as [24-26]

$$
\Delta b(t)=L_{s}\left(\frac{G_{c}}{L_{s}}\right)^{D-1} \sum_{n=0}^{n_{\max }} \frac{\cos \left(2 \pi \gamma^{n} t / L_{s}\right)}{\gamma^{(2-D) n}}, \quad(1<D<2, \gamma>1)
$$

where $L_{s}$ is the sampling width, $\gamma^{n}$ represents space frequency of flank profile, $G_{c}$ is the characteristic scale coefficient, and $D$ represents the fractal dimension controlling the complexity of the fractal curve. The relationship between $G_{c}$ and $R_{q}$ is given by

$$
R_{q}=\left[\frac{G_{c}^{2(D-1)}}{2 \ln \gamma} \frac{1}{4-2 D}\left(\frac{1}{\omega_{k}^{(4-2 D)}} \frac{1}{\omega_{h}^{(4-2 D)}}\right)\right]^{0.5},
$$

where $\omega_{k}$ and $\omega_{h}$ are, respectively, equivalent to lower cutoff frequency and upper cutoff frequency. When the gear system appeared vibration, the center distance of gears is changed. By changing the center distance of gears, the backlash must be generated with volatility. The vibration variation backlash $b(t)$ and dynamic center distance $a$ can be determined as $[27,28]$

$$
\begin{aligned}
a & =\sqrt{\left(a_{0} \cos \alpha_{0}+x_{2}-x_{1}\right)^{2}+\left(y_{2}-y_{1}-a_{0} \sin \alpha_{0}\right)^{2}}, \\
b(t) & =\left(a-a_{0}\right) \tan \varphi_{1}+b_{0},
\end{aligned}
$$

where $a_{0}$ represents initial center distance, $\alpha_{0}$ is the pressure angle, and $b_{0}$ represents fixed backlash. The simplified center distance model is shown in Figure 5(a).

When crack occurs on the teeth surfaces, the dynamic center distance $a$ is increased. The dynamic backlash with crack is given by

$$
b_{h}(t)=b(t)+\Delta b(t)
$$

2.4. The Friction Force. Due to the meshing contact points located in different positions, the direction of friction force must be different. Thus, the frictional force changes periodically with the changing of contact points. Friction is given by

$$
\begin{aligned}
F_{f} & =\sum_{i=1}^{j} \mu \lambda_{i}\left(v_{s}\right) F_{m i}, \quad j=1,2, \\
\lambda\left(v_{s}\right) & =\left\{\begin{array}{cl}
1, & v_{s}>0, \\
0, & v_{s}=0, \\
-1, & v_{s}<0,
\end{array}\right.
\end{aligned}
$$

where the state is the single tooth meshing at $j=1$, while the state is double tooth meshing at $j=2 . \lambda\left(v_{s}\right)$ is the direction coefficient of the friction force, $\mu$ is the friction coefficient of the gear surface, and $F_{m i}$ is the dynamic meshing force.

$v_{s}$ represents relative sliding velocity of the meshing point $M$ of the tooth pairs in Figure 5(b), which can be determined as

$$
v_{S}=v_{M 1} \sin \varphi_{1}-v_{M 2} \sin \varphi_{2},
$$

where $v_{M 1}$ and $v_{M 2}$ are, respectively, on the meshing point $M$ and are described as follows: 


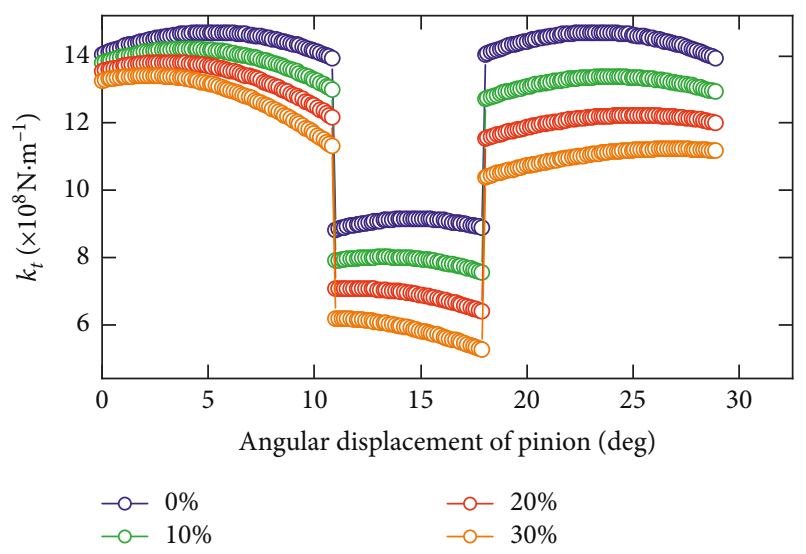

FIGURE 3: The time-varying meshing stiffness.

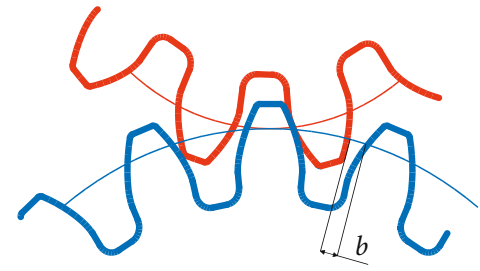

Figure 4: Sketch of backlash.

$$
\begin{aligned}
& v_{M 1}=\omega_{1} \overline{O_{1} M}, \\
& v_{M 2}=\omega_{1} \overline{O_{2} M} .
\end{aligned}
$$

Friction torque is determined as

$$
\begin{aligned}
& T_{f 1}=F_{f} \overline{N_{1} M}, \\
& T_{f 2}=F_{f} \overline{N_{2} M},
\end{aligned}
$$

where $\overline{N_{1} M}$ and $\overline{N_{2} M}$ are, respectively, the friction arms and are defined as

$$
\begin{aligned}
& \overline{N_{1} M}=\left(r_{b 1}+r_{b 2}\right) \tan \alpha-\sqrt{r_{a 2}^{2}-r_{b 2}^{2}}+r_{b 1} \omega_{1} t, \\
& \overline{N_{2} M}=\left(r_{b 1}+r_{b 2}\right) \tan \alpha-\overline{N_{1} M} .
\end{aligned}
$$

2.5. Ball Bearing Model. In Figure 6, the ball bearing model is shown. The outer ring is fastened to the bearing chock. The inner ring is fastened to the shaft. The rolling elements are evenly distributed between inner and outer rings. $v_{i}$ and $v_{o}$ representing the contact point velocities between the rolling elements and inner/outer rings are given by

$$
\begin{aligned}
& v_{\mathrm{i}}=\omega_{i} \cdot r, \\
& v_{\mathrm{o}}=\omega_{\mathrm{o}} \cdot R,
\end{aligned}
$$

where $R$ and $r$ are radii of inner and outer rings, and the angular velocities of inner and outer rings are $\omega_{i}$ and $\omega_{\mathrm{o}}$. The velocity of cage is expressed as

$$
v_{b}=\frac{\left(v_{\mathrm{o}}+v_{\mathrm{i}}\right)}{2}=\frac{\left(\omega_{\mathrm{o}} R+\omega_{i} r\right)}{2} .
$$

Due to $\omega_{i}=\omega$ and $\omega_{\mathrm{o}}=0$, the angular velocity of cage $\omega_{b}$ is given by

$$
\omega_{b}=\frac{2 v_{b}}{(R+r)}=\frac{\omega_{i} \cdot r}{(R+r)} .
$$

The momentary angular displacement $\varphi_{i}^{1}$ of the $i$ th rolling element is given by

$$
\varphi_{i}^{1}=\omega_{b} \cdot t+\frac{2 \pi(i-1)}{N_{b}}, \quad i=1,2,3, \ldots, N_{b},
$$

where $N_{b}$ is the number of rolling balls and $\omega_{b}$ is the angular velocity of the cage.

The deformation of the $i$ th rolling ball can be described by

$$
\delta_{i}^{1}=x \cos \varphi_{i}^{1}+y \sin \varphi_{i}^{1}-\gamma_{0}
$$

where $\gamma_{0}$ represents bearing clearance. The Hertz contact theory is employed for computing contact force. Contact force of the $i$ th rolling element $f_{i}$ can be determined as

$$
\begin{aligned}
f_{i}= & K_{b}\left(x \cos \varphi_{i}^{1}+y \sin \varphi_{i}^{1}-\gamma_{0}\right)^{3 / 2} \\
& \cdot H\left(x \cos \varphi_{i}^{1}+y \sin \varphi_{i}^{1}-\gamma_{0}\right)
\end{aligned}
$$

where $K_{b}$ is the Hertz contact stiffness and $H(x)$ is the Heaviside function. So, the bearing forces are given by

$$
\begin{aligned}
& F_{x j}=\sum_{i=1}^{N_{b}} f_{i} \cos \varphi_{i}^{1}=F \cos \varphi_{i}^{1}, \\
& F_{y j}=\sum_{i=1}^{N_{b}} f_{i} \sin \varphi_{i}^{1}=F \sin \varphi_{i}^{1}, \\
& \qquad j=1,2,3,4 .
\end{aligned}
$$

2.6. Mathematical Model of the GRBS. The nonlinear differential equation (33) of the GRBS are evolved from Lagrange's equation.

$c_{t 1}, c_{t 2}, c_{s 1}$, and $c_{s 2}$ are torsion and bending damping, respectively, and are given by 


$$
\begin{aligned}
& c_{t 1}=2 \xi_{t} \sqrt{\frac{k_{t 1}}{\left(1 / I_{d}\right)+\left(1 / I_{1}\right)}}, \\
& c_{t 2}=2 \xi_{t} \sqrt{\frac{k_{t 2}}{\left(1 / I_{2}\right)+\left(1 / I_{g}\right)}}, \\
& c_{s 1}=2 \xi_{s} \sqrt{\frac{k_{s 1}}{\left(1 / m_{b 1}\right)+\left(1 / m_{1}\right)}}, \\
& c_{s 2}=2 \xi_{s} \sqrt{\frac{k_{s 2}}{\left(1 / m_{b 3}\right)+\left(1 / m_{2}\right)}}, \\
& J_{d} \ddot{\theta}_{d}+c_{t 1}\left(\dot{\theta}_{d}-\dot{\theta}_{1}\right)+k_{t 1}\left(\theta_{d}-\theta_{1}\right)=T_{d} \text {, } \\
& m_{1} \ddot{x}_{1}+c_{s 1}\left(\dot{x}_{1}-\xi_{2} \dot{x}_{b 1}-\xi_{1} \dot{x}_{b 2}\right)+k_{s 1}\left(x_{1}-\xi_{2} x_{b 1}-\xi_{1} \dot{x}_{b 2}\right) \\
& =m_{1} \rho_{1} \ddot{\theta}_{1} \sin \left(\omega_{1} t+\theta_{1}\right)+m_{1} \rho_{1}\left(\omega_{1}+\dot{\theta}_{1}\right)^{2} \cos \left(\omega_{1} t+\theta_{1}\right)-F_{f}, \\
& m_{1} \ddot{y}_{1}+c_{s 1}\left(\dot{y}_{11}-\xi_{2} \dot{y}_{b 1}-\xi_{1} \dot{y}_{b 2}\right)+k_{s 1}\left(y_{1}-\xi_{2} y_{b 1}-\xi_{1} y_{b 2}\right) \\
& =m_{1} \rho_{1}\left(\omega_{1}+\dot{\theta}_{1}\right)^{2} \sin \left(\omega_{1} t+\theta_{1}\right)-m_{1} \rho_{1} \ddot{\theta}_{1} \cos \left(\omega_{1} t+\theta_{1}\right)-F_{m}-m_{1} g, \\
& \left(J_{1}+m_{1} \rho_{1}^{2}\right) \ddot{\theta}_{1}+c_{t 1}\left(\dot{\theta}_{1}-\dot{\theta}_{d}\right)+k_{t 1}\left(\theta_{1}-\theta_{d}\right) \\
& =m_{1} \rho_{1} \sin \left(\omega_{1} t+\theta_{1}\right) \ddot{x}_{1}-m_{1} \rho_{1} \cos \left(\omega_{1} t+\theta_{1}\right) \ddot{y}_{1}-F_{m} r_{b 1}+T_{f 1}, \\
& m_{2} \ddot{x}_{2}+c_{s 2}\left(\dot{x}_{2}-\xi_{4} \dot{x}_{b 3}-\xi_{3} \dot{x}_{b 4}\right)+k_{s 2}\left(x_{2}-\xi_{4} x_{b 3}-\xi_{3} x_{b 4}\right) \\
& =m_{2} \rho_{2} \ddot{\theta}_{2} \sin \left(\omega_{2} t+\theta_{2}\right)+m_{2} \rho_{2}\left(\omega_{2}+\dot{\theta}_{2}\right)^{2} \cos \left(\omega_{2} t+\theta_{2}\right)+F_{f}, \\
& m_{2} \ddot{y}_{2}+c_{S 2}\left(\dot{y}_{2}-\xi_{4} \dot{y}_{b 3}-\xi_{3} \dot{y}_{b 4}\right)+k_{s 1}\left(y_{2}-\xi_{4} y_{b 3}-\xi_{3} y_{b 4}\right) \\
& =m_{2} \rho_{2}\left(\omega_{2}+\dot{\theta}_{2}\right)^{2} \sin \left(\omega_{2} t+\theta_{2}\right)-m_{2} \rho_{2} \ddot{\theta}_{2} \cos \left(\omega_{2} t+\theta_{2}\right)-F_{m}-m_{2} g, \\
& \left(J_{2}+m_{2} \rho_{2}^{2}\right) \ddot{\theta}_{2}+c_{t 2}\left(\dot{\theta}_{2}-\dot{\theta}_{g}\right)+k_{t 2}\left(\theta_{2}-\theta_{g}\right) \\
& =m_{2} \rho_{2} \sin \left(\omega_{2} t+\theta_{2}\right) \ddot{x}_{2}-m_{2} \rho_{2} \cos \left(\omega_{2} t+\theta_{2}\right) \ddot{y}_{2}-F_{m} r_{b 2}-T_{f 2}, \\
& m_{b 1} \ddot{x}_{b 1}+c_{s 1} \xi_{2}\left(-\dot{x}_{1}+\xi_{2} \dot{x}_{b 1}+\xi_{1} \dot{x}_{b 2}\right)+c_{b x 1} \dot{x}_{b 1}+k_{s 1} \xi_{2}\left(-x_{1}+\xi_{2} x_{b 1}+\xi_{1} x_{b 2}\right)=F_{x 1} \text {, } \\
& m_{b 1} \ddot{y}_{b 1}+c_{s 1} \xi_{2}\left(-\dot{y}_{1}+\xi_{2} \dot{y}_{b 1}+\xi_{1} \dot{y}_{b 2}\right)+c_{b y 1} \dot{y}_{b 1}+k_{s 1} \xi_{2}\left(-y_{1}+\xi_{2} y_{b 1}+\xi_{1} y_{b 2}\right)=F_{y 1}-m_{b 1} g \text {, } \\
& m_{b 2} \ddot{x}_{b 2}+c_{s 1} \xi_{1}\left(-\dot{x}_{1}+\xi_{2} \dot{x}_{b 1}+\xi_{1} \dot{x}_{b 2}\right)+c_{b x 2} \dot{x}_{b 2}+k_{s 1} \xi_{1}\left(-x_{1}+\xi_{2} x_{b 1}+\xi_{1} x_{b 2}\right)=F_{x 2} \text {, } \\
& m_{b 2} \ddot{y}_{b 2}+c_{s 1} \xi_{1}\left(-\dot{y}_{1}+\xi_{2} \dot{y}_{b 1}+\xi_{1} \dot{y}_{b 2}\right)+c_{b y 2} \dot{y}_{b 1}+k_{s 1} \xi_{1}\left(-y_{1}+\xi_{2} y_{b 1}+\xi_{1} y_{b 2}\right)=F_{y 2}-m_{b 2} g \text {, } \\
& m_{b 3} \ddot{x}_{b 3}+c_{s 2} \xi_{4}\left(-\dot{x}_{2}+\xi_{4} \dot{x}_{b 3}+\xi_{3} \dot{x}_{b 4}\right)+c_{b x 3} \dot{x}_{b 3}+k_{s 2} \xi_{4}\left(-x_{2}+\xi_{4} x_{b 3}+\xi_{3} x_{b 4}\right)=F_{x 3} \text {, } \\
& m_{b 3} \ddot{y}_{b 3}+c_{s 2} \xi_{4}\left(-\dot{y}_{2}+\xi_{4} \dot{y}_{b 3}+\xi_{3} \dot{y}_{b 4}\right)+c_{b y 3} \dot{y}_{b 3}+k_{s 2} \xi_{4}\left(-y_{2}+\xi_{4} y_{b 3}+\xi_{3} y_{b 4}\right)=F_{y 3}-m_{b 3} g \text {, } \\
& m_{b 4} \ddot{x}_{b 4}+c_{s 2} \xi_{3}\left(-\dot{x}_{2}+\xi_{4} \dot{x}_{b 3}+\xi_{3} \dot{x}_{b 4}\right)+c_{b x 4} \dot{x}_{b 4}+k_{s 2} \xi_{3}\left(-x_{2}+\xi_{4} x_{b 3}+\xi_{3} x_{b 4}\right)=F_{x 4} \text {, } \\
& m_{b 4} \ddot{y}_{b 4}+c_{s 2} \xi_{3}\left(-\dot{y}_{2}+\xi_{4} \dot{y}_{b 3}+\xi_{3} \dot{y}_{b 4}\right)+c_{b y 4} \dot{y}_{b 4}+k_{s 2} \xi_{3}\left(-y_{2}+\xi_{4} y_{b 3}+\xi_{3} y_{b 4}\right)=F_{y 4}-m_{b 4} g \text {, } \\
& J_{g} \ddot{\theta}_{g}+c_{t 2}\left(\dot{\theta}_{g}-\dot{\theta}_{2}\right)+k_{t 2}\left(\theta_{g}-\theta_{2}\right)=-T_{g} \text {, }
\end{aligned}
$$

where $k_{s 1}, k_{s 2}, k_{t 1}$, and $k_{t 2}$ represent bending stiffness and torsion stiffness of the shafts. $c_{b i j}(i=x, y)(j=1,2,3,4)$ are equivalent bearing damping in the directions $x$ and $y$.

The gear-rotor-bearing model with strong nonlinear and time-varying characteristics is established. The dynamic backlash and time-varying meshing stiffness with crack are included in the system. The main parameters are shown in Tables 1 and 2 .

\section{Dynamic Response and Discussion}

3.1. Comparison of Three Backlash Models. In the section, the three models about backlash are explored by the same parameters. The time-domain waveforms and frequency spectra are shown in Figures 7 and 8. The waveform of fixed backlash is stable, as is shown in Figure 7(a). The vibration waveform of dynamic backlash based on the dynamic center 


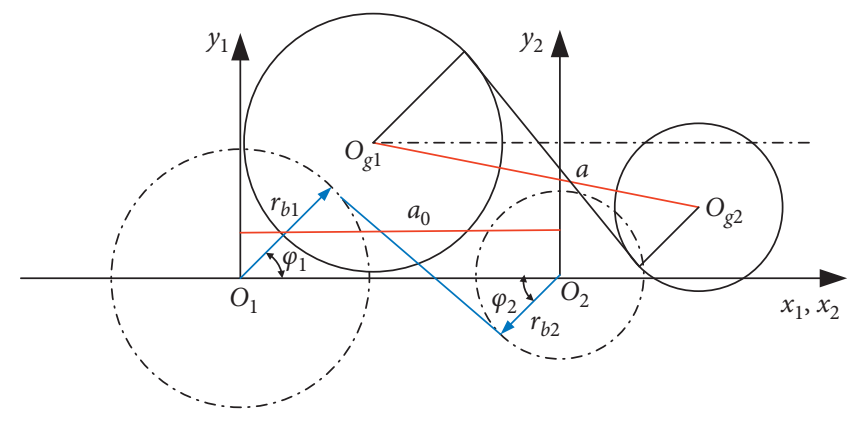

(a)

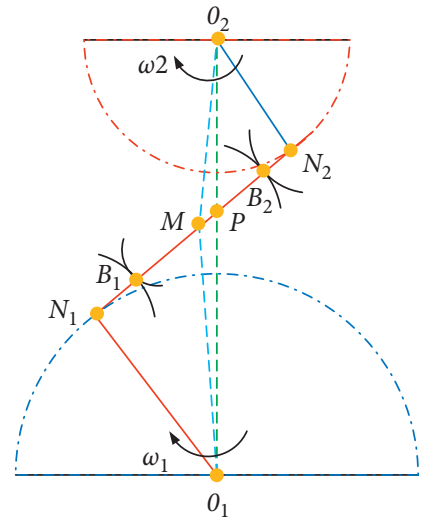

(b)

FiguRE 5: (a) Simplified center distance model and (b) simplified sketch of meshing.

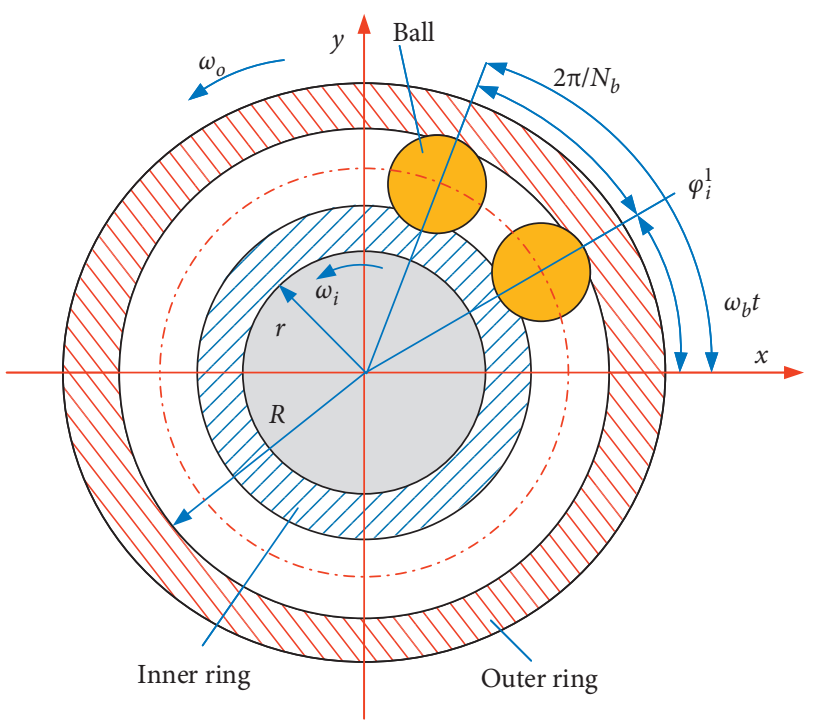

Figure 6: Rolling bearing model.

distance model produces significant fluctuations in Figure 7(b). It is clearly seen that the vibration displacement fluctuations of the compound dynamic backlash model are the biggest in Figure 7(c). In addition, the amplitude of $10 f_{\mathrm{r} 1}$ has an obvious difference among Figures 8(a)-8(c). The frequency components of compound dynamic backlash are more than the others. It is distinct that the waveforms, frequency components, and amplitude are most different for the three models.

3.2. Dynamic Response of the Gear System with a Tooth Root Crack. On the basis of the gear transmission system model equation (30), the vibration responses of the gear system with different crack depths are listed to investigate the effect on the system. Fractal dimension $D$ is assumed to be 1.5 , and friction coefficient $\mu=0.05$. The crack depth is set from zero to forty percent of the tooth thickness. Considering the different spindle speeds, such as $600 \mathrm{r} / \mathrm{min}, 1800 \mathrm{r} / \mathrm{min}$, and $3000 \mathrm{r} / \mathrm{min}$, the response characteristics are investigated under the different crack depths. In Figures 9(a)-9(d), the RMS of each significant parameter is presented, including the dynamic meshing force $F_{m}$, variation of dynamic center distance of gears $\Delta a$, the comprehensive elastic deformation $\delta(t)$, and the backlash $b_{h}(t)$ of the gear. Apparently, in Figure 7(a), it is stationary for the $600 \mathrm{r} / \mathrm{min}$ of the blue line with increasing crack depth. Within the limits of $0-30 \%$, the RMS green curve of $b_{h}(t)$ is little different. When the rotational speed is $3000 \mathrm{r} / \mathrm{min}$, the maximum value of the red line of $b_{h}(t)$ is crack $22 \%$.

The dynamic meshing force $F_{m}$ increases with the increase in crack depth in the range of $0 \%$ and $30 \%$ in Figure 9 (b), setting to $1800 \mathrm{r} / \mathrm{min}$ or $3000 \mathrm{r} / \mathrm{min}$. It indicates that $F_{m}$ increases with crack depth within the limits of high speed. But, it slightly decreases in the range of low speed. When the crack is severe in the range of $30 \%$ and $40 \%, F_{m}$ of $600 \mathrm{r} / \mathrm{min}$ and $3000 \mathrm{r} / \mathrm{min}$ has a rapid, fluctuating increase. However, $F_{m}$ of $1800 \mathrm{r} / \mathrm{min}$ is a rapid fall.

The RMS of comprehensive elastic deformation $\delta(t)$ speed increases with the increase in crack depth in Figure 9(c). But it is a fall with the increase in speed. The variation of center distance $\Delta a\left(\Delta a=a-a_{0}\right)$ is shown in Figures $9(\mathrm{~d})$ and $10(\mathrm{a})-10(\mathrm{c})$. The larger the speed set, the smaller the variation value of center distance. An enlarged view of each speed is shown in Figure 10.

When the speed is low, the RMS of $\Delta a$ slowly increases in the range of $0 \%$ and $30 \%$, and it grows rapidly within the limit of $30 \%$ and $40 \%$. With increasing speed, an increase in volatility is shown in Figures 10(b) and 10(c). The value corresponding to the crack $22 \%$ is the minimum value. The value corresponding to the crack $40 \%$ is the maximum value.

3.3. Vibration Responses and Frequency Characteristics with Different Crack Depths. In order to study the effect of crack on dynamic responses of the system, the time-domain waveform and frequency-domain response are shown with different crack depths. The rotational speed is set to $3000 \mathrm{r} / \mathrm{min}$. The crack depth is set to $0 \%, 10 \%$, and $30 \%$ of the tooth thickness. Figures 11(a)-11(e), 12(a)-12(e), and 13(a)-13(e) display the vibration displacements of the gears and the bearings, which are, respectively, at $0 \%$, 
TABLE 1: Parameters of the gear-bearing system.

\begin{tabular}{lcc}
\hline Parameter & Symbol & Numerical value \\
\hline Pressure angle & $\alpha$ & $20^{\circ}$ \\
Moment of inertia & $J_{1} / J_{2}$ & $7.1 \times 10^{-3} / 1.39 \times 10^{-4} \mathrm{~kg} \cdot \mathrm{m}^{2}$ \\
Moment of inertia of input/output & $J_{d} / J_{g}$ & $1.25 \times 10^{-4} / 5.75 \times 10^{-4} \mathrm{~kg} \cdot \mathrm{m}^{2}$ \\
Mass & $m_{1} / \mathrm{m}_{2}$ & $2.6 / 0.9 \mathrm{~kg}$ \\
Stiffness of bearings & $k_{1} / k_{2}$ & $2 / 2 \times 10^{8} \mathrm{~N} \cdot \mathrm{m}^{-1}$ \\
Teeth & $z_{1} / z_{2}$ & $30 / 20$ \\
Module & $m$ & $4 \mathrm{~mm}$ \\
Tooth width & $L$ & $0.03 \mathrm{~m}$ \\
Mean/amplitude of the transmission error & $e_{0} / e_{r}$ & $2 \times 10^{-5} / 3 \times 10^{-5} \mathrm{~m}$ \\
Eccentricity & $\rho_{1} / \rho_{2}$ & $3 \times 10^{-5} / 2 \times 10^{-5} \mathrm{~m}$ \\
Driving torque & $T_{1}$ & $270 \mathrm{~N} \cdot \mathrm{m}$ \\
Loading torque & $T_{\mathrm{d}}$ & $160 \mathrm{~N} \cdot \mathrm{m}$ \\
Damping ratio of gear meshing & $\xi_{m}$ & 0.02 \\
Damping ratio of shaft & $\xi_{s} / \xi_{t}$ & $0.1 / 0.1$ \\
\hline
\end{tabular}

TABLE 2: Model parameters of the bearing.

\begin{tabular}{lcc}
\hline Parameter & Symbol & Numerical value \\
\hline Outer ring radius of bearing & $R_{1} / R_{2}$ & $0.031 / 0.021 \mathrm{~m}$ \\
Inner ring radius of bearing & $r_{1} / r_{2}$ & $0.02 / 0.015 \mathrm{~m}$ \\
Contact stiffness & $K_{\mathrm{b} 1} / K_{\mathrm{b} 2}$ & $13.34 \times 10^{9} / 10.56 \times 10^{9} \mathrm{Nm}^{3 / 2}$ \\
Bearing clearance & $\gamma_{01} / \gamma_{02}$ & $3 \times 10^{-5} / 2 \times 10^{-5} \mathrm{~m}$ \\
Ball number & $N_{1} / N_{2}$ & $14 / 18$ \\
\hline
\end{tabular}

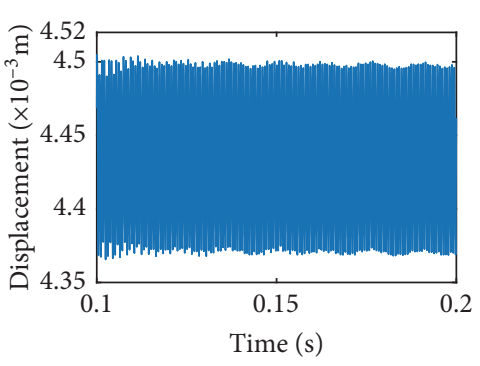

(a)

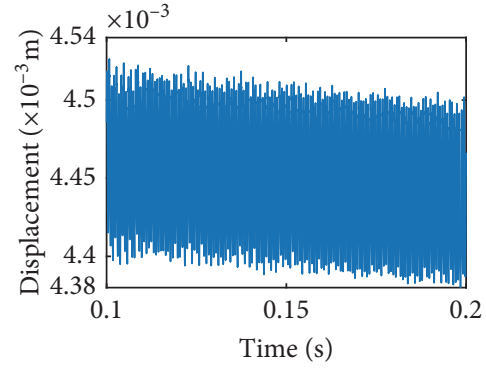

(b)

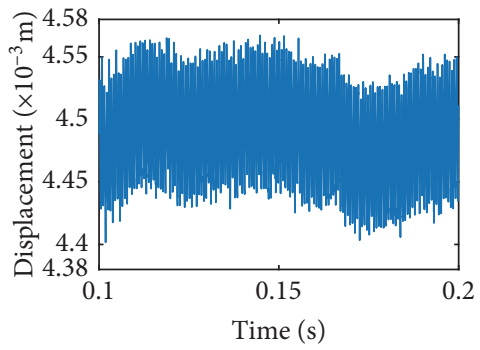

(c)

Figure 7: Vibration displacement in $\theta_{1}$ direction: (a) fixed backlash model, (b) backlash based on dynamic center distance model, and (c) compound dynamic backlash model (in this paper).

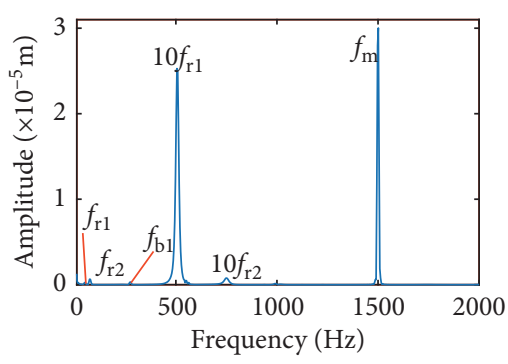

(a)

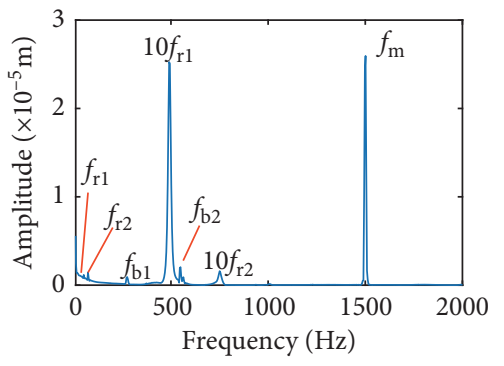

(b)

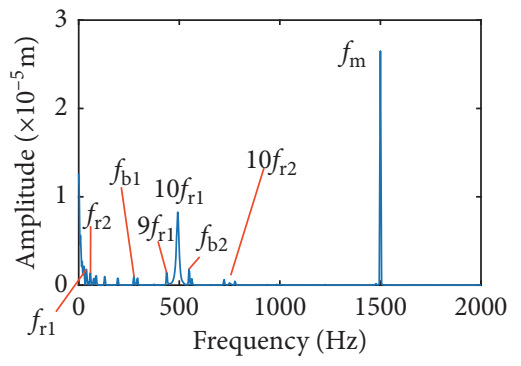

(c)

Figure 8: Frequency spectra in $\theta_{1}$ direction: (a) fixed backlash model, (b) backlash based on dynamic center distance model, and (c) compound dynamic backlash model (in this paper).

$10 \%$, and $30 \%$ of the tooth thickness. Figures (14)-(16) show the frequency domain responses at the different crack depths.
For the healthy gear system shown in Figure 11(b), the fluctuation of the vibration displacement in torsional direction $\left(\theta_{1}\right)$ is more obvious than others. It indicates that the 


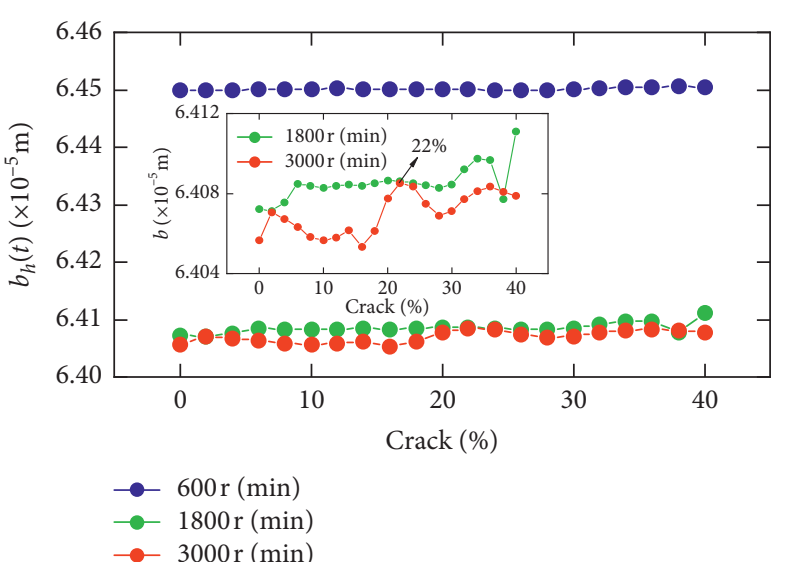

(a)

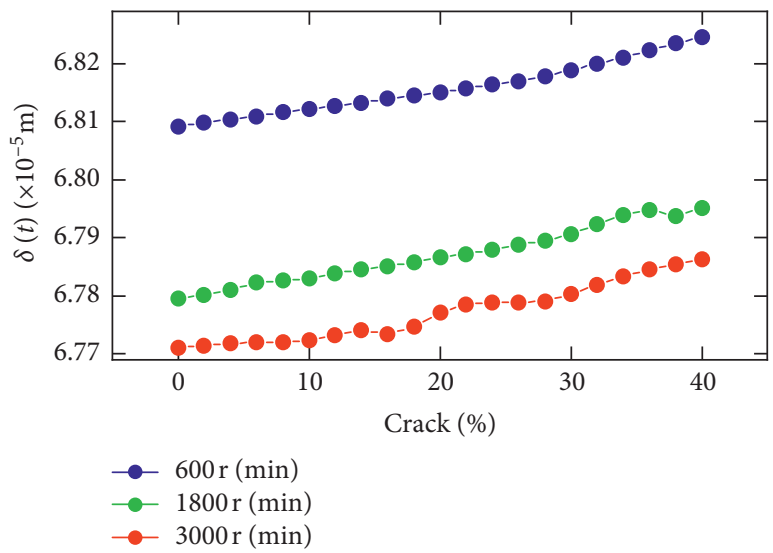

(c)

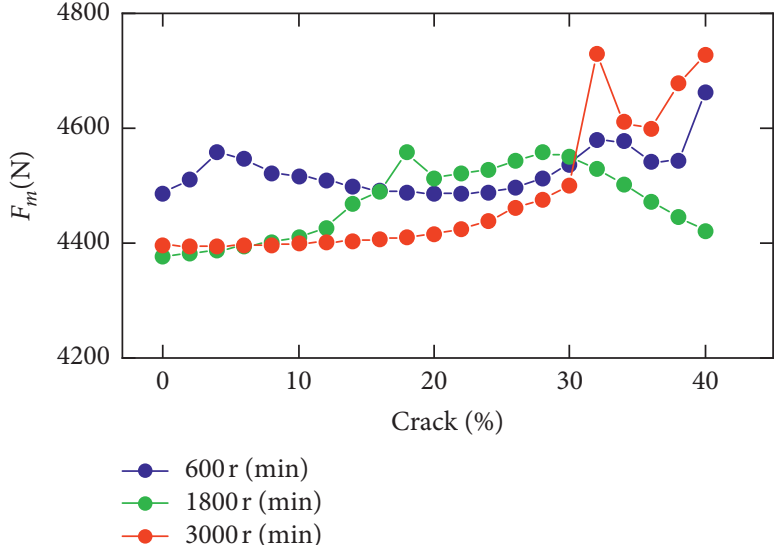

(b)

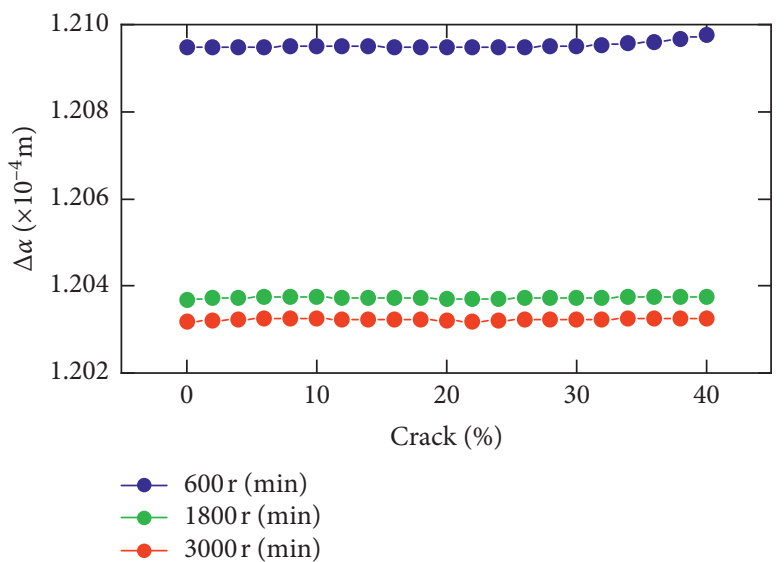

(d)

FIGURE 9: RMS variations of nonlinear parameters: (a) dynamic backlash, (b) meshing force, (c) comprehensive elastic deformation, and (d) variation of center distance.

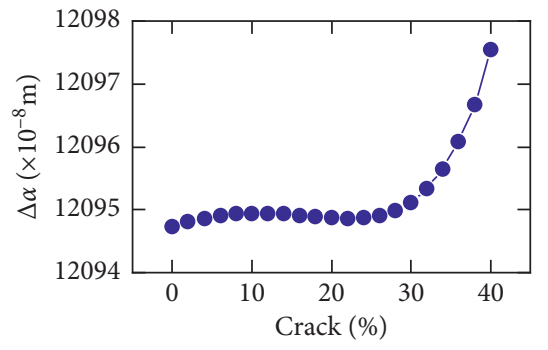

(a)

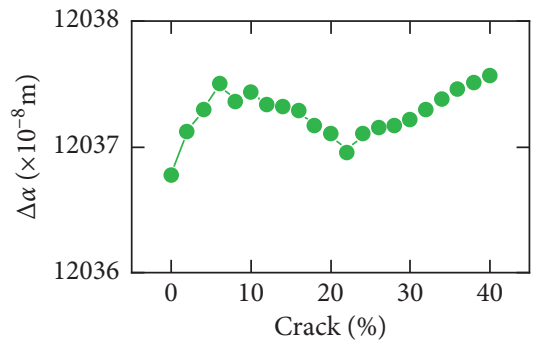

(b)

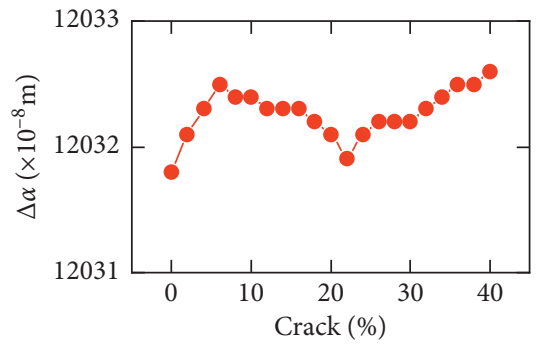

(c)

FIGURe 10: Partial enlarged drawing of variation of center distance: (a) $600 \mathrm{r} / \mathrm{min}$, (b) $1800 \mathrm{r} / \mathrm{min}$, and (c) $3000 \mathrm{r} / \mathrm{min}$.

vibration response in torsional direction $\left(\theta_{1}\right)$ is more sensitive to nonlinear factors and excitation. In Figure 11(e), those factors have less impact on the vibration of the bearing.

The time-domain waveform will exist as a pulse in theory when a tooth root crack appears. Though the variation of waveform in all directions is obvious in Figures 12 and 13 , a pulse is covered with the fluctuation caused by other excitation factors. So, the pulse form that should have been generated is not so obvious. The amplitude of the pinion in $x_{2}$ direction is distinctly increased because of the crack fault, and the change of waveform is also obvious in Figures 12(c) and 13(c). In addition, the amplitude of the other directions has a slight increase, as is shown in Figures 12(a), 12(b), 13(a), and 13(b). The vibration response of the bearing is among those least affected in Figures 12(d), 12(e), 13(d), and 13(e).

Obviously, the effect of a tooth root crack on vibration response of the gear system components is different. In the case of vibration response in $x_{2}$ direction, the statistic datum from the results shows that the amplitude of crack $10 \%$ 


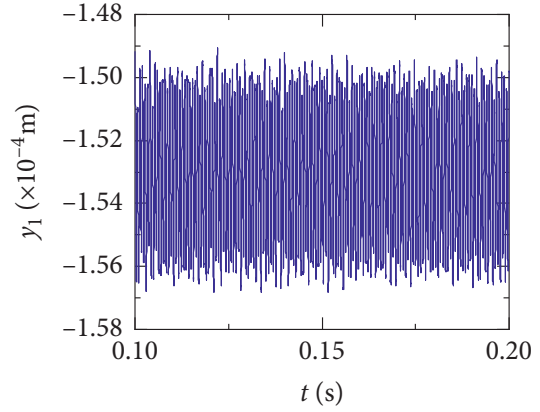

(a)

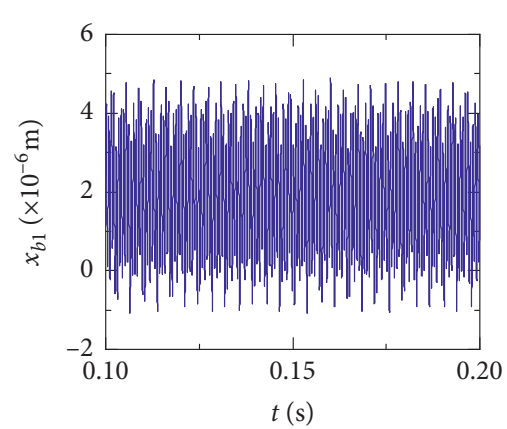

(d)

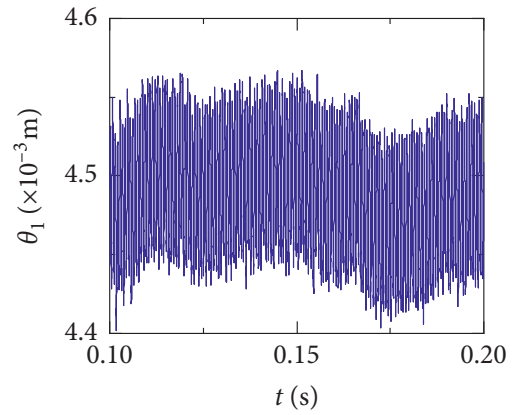

(b)

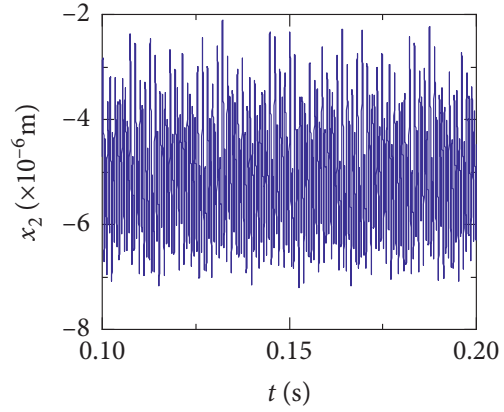

(c)

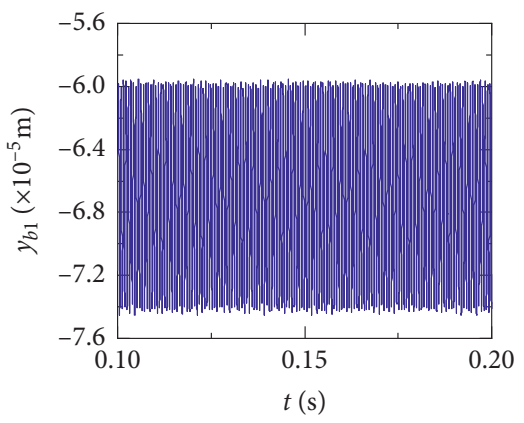

(e)

FIGURE 11: Time-domain waveforms of the healthy gear system in (a) $y_{1}$, (b) $\theta_{1}$, (c) $x_{2}$, (d) $x_{b 1}$, and (e) $y_{b 1}$ directions.

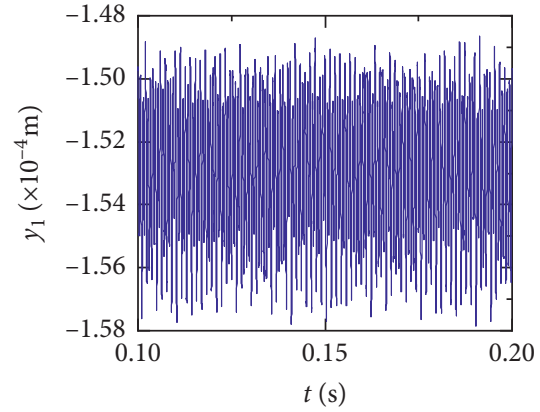

(a)

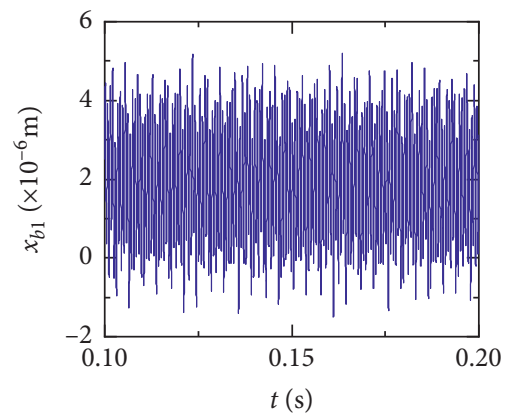

(d)

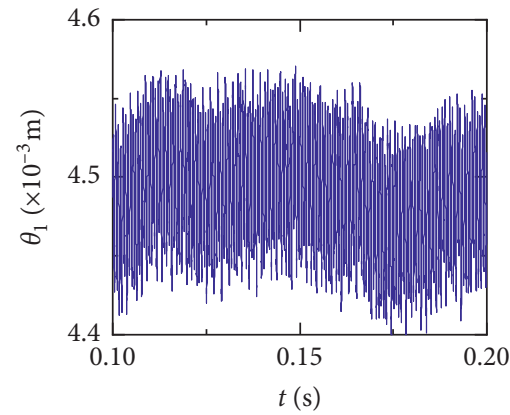

(b)

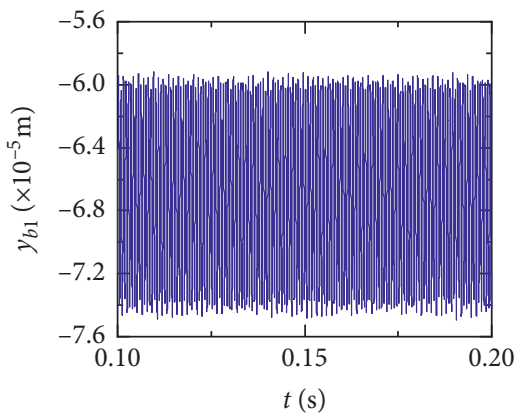

(e)

Figure 12: Time-domain waveforms of crack $10 \%$ in (a) $y_{1}$, (b) $\theta_{1}$, (c) $x_{2}$, (d) $x_{b 1}$, and (e) $y_{b 1}$ directions.

increases by 1.428 times than the healthy system. The amplitude increases by 1.735 times than the healthy system. But the rate of increase of vibration amplitude on the bearing does not exceed 15\%. In addition, the time-domain waveform fluctuates more intense in $x_{2}$ direction. For transverse $\left(x_{b 1}\right)$ and longitudinal $\left(y_{b 1}\right)$ vibrations of the bearing, the vibration waveforms become more disordered because a tooth root crack appears, as is shown in 


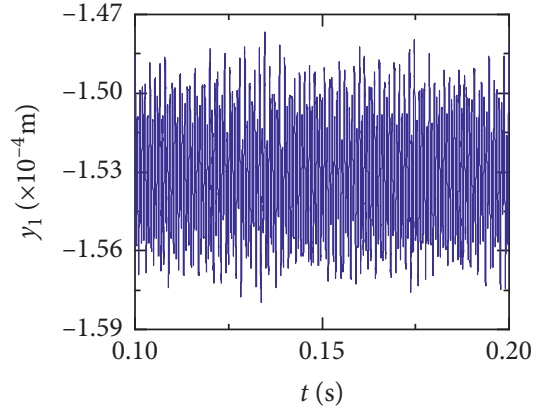

(a)

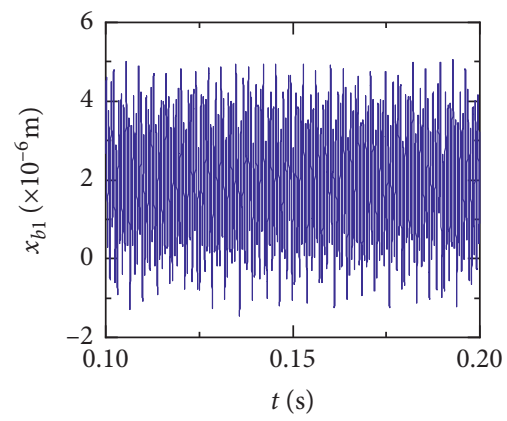

(d)

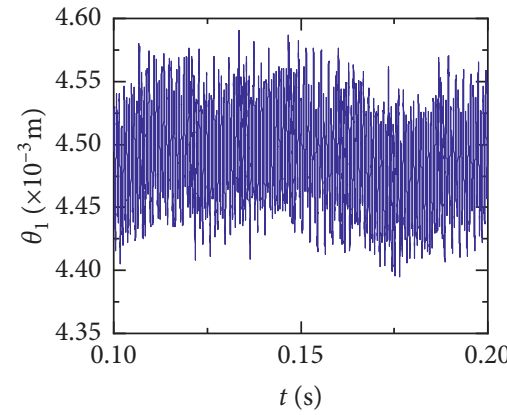

(b)

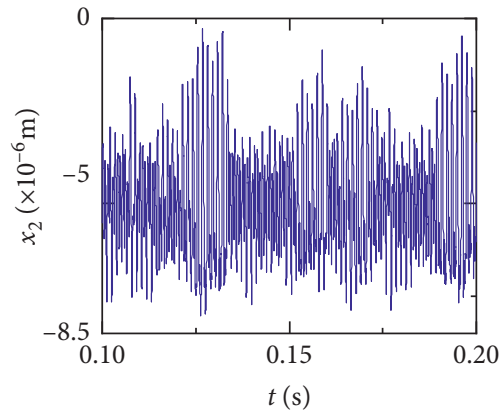

(c)

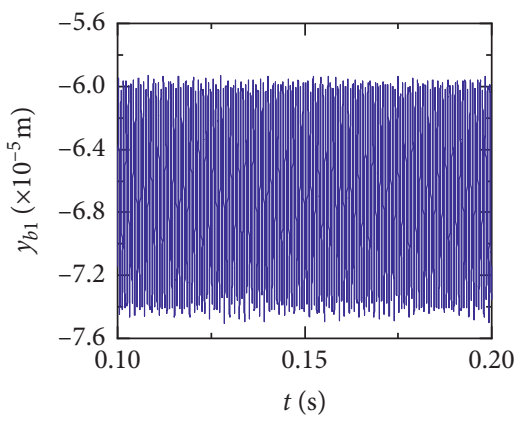

(e)

FIGURE 13: Time-domain waveforms of crack $30 \%$ in (a) $y_{1}$, (b) $\theta_{1}$, (c) $x_{2}$, (d) $x_{b 1}$, and (e) $y_{b 1}$ directions.

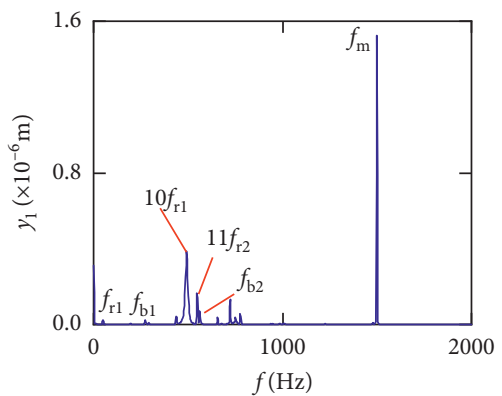

(a)

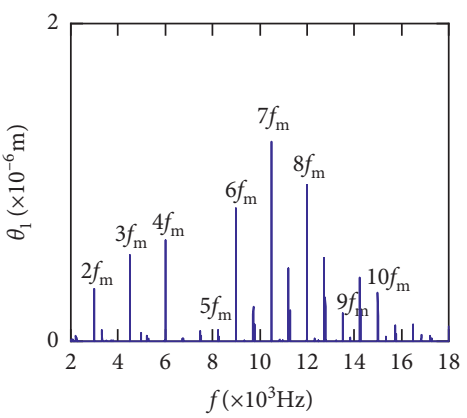

(d)

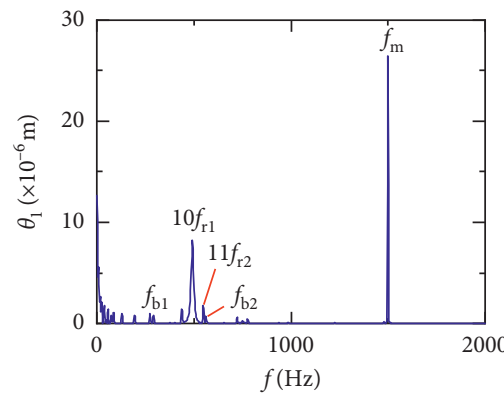

(b)

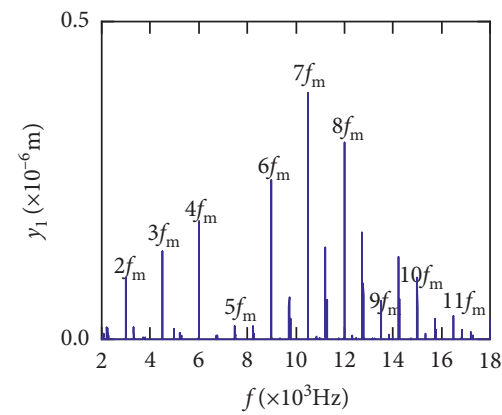

(e)

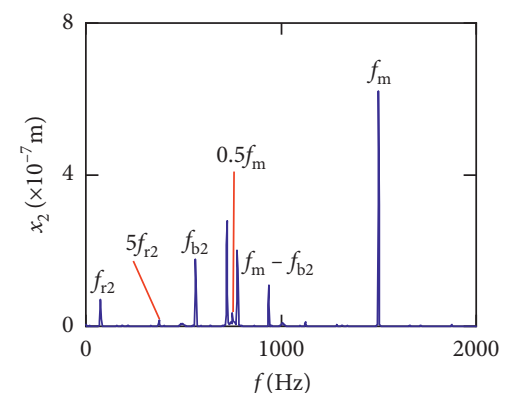

(c)

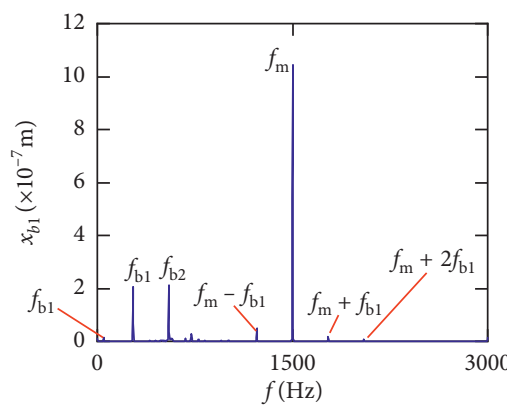

(f)

Figure 14: Continued. 


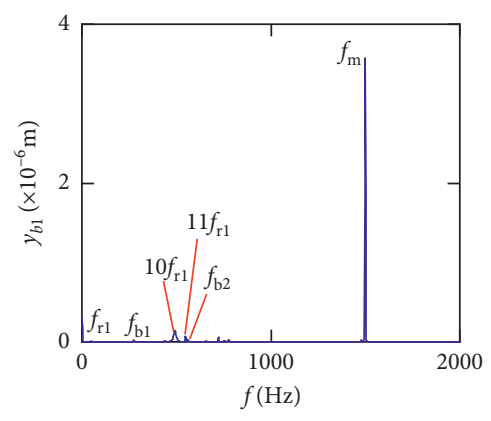

(g)

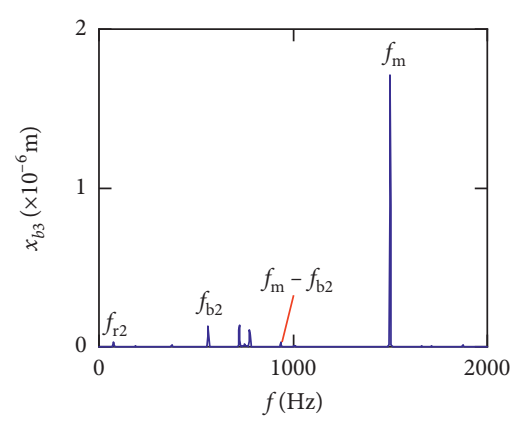

(h)

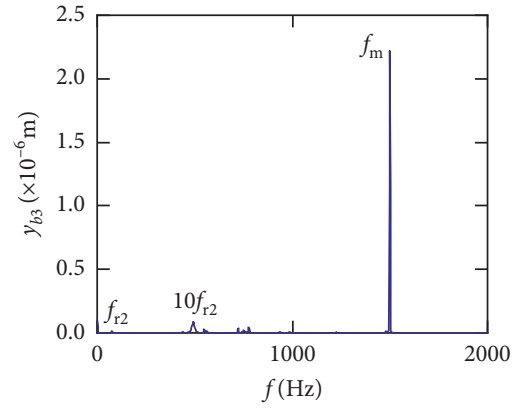

(i)

FIGURE 14: Frequency spectra of the healthy gear in (a) $y_{1}$, (b) $\theta_{1}$, (c) $x_{2}$, (d) $\theta_{1}$, (e) $y_{1}$, (f) $x_{b 1}$, (g) $y_{b 1}$, (h) $x_{b 3}$, and (i) $y_{b 3}$ directions.

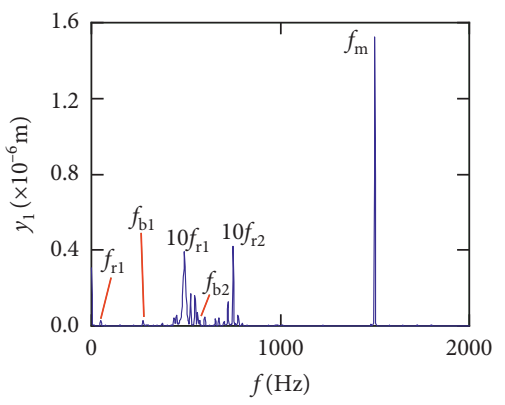

(a)

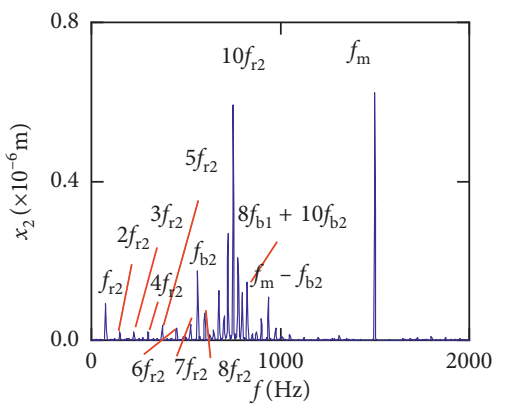

(d)

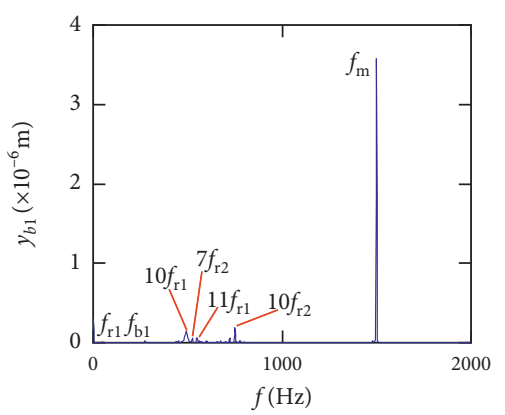

(g)

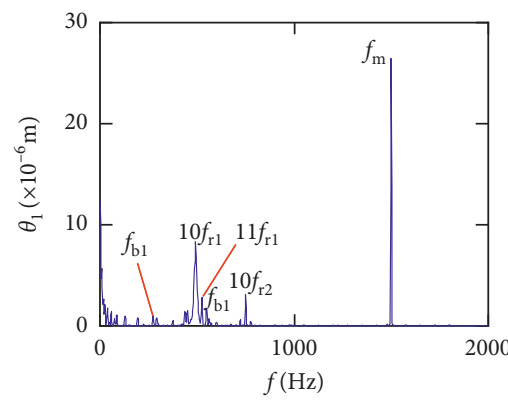

(b)

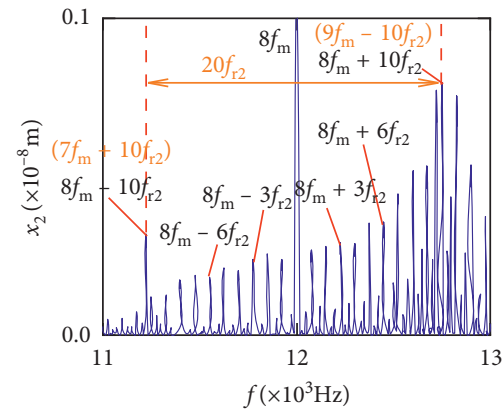

(e)

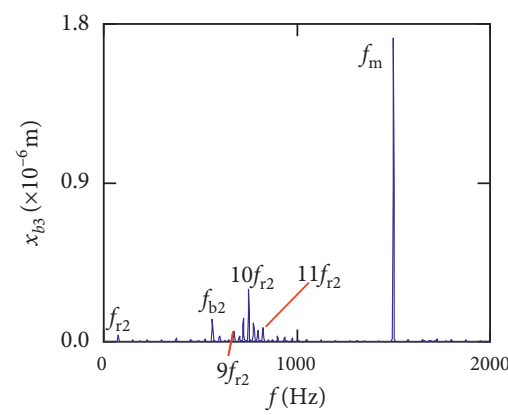

(h)

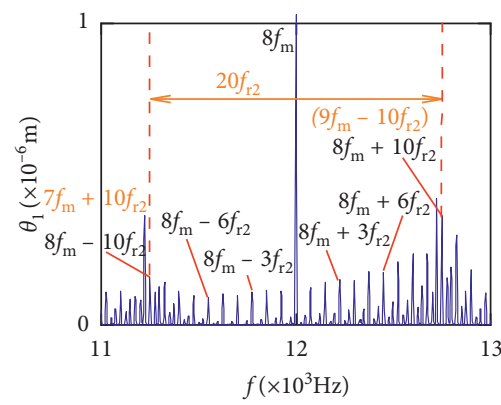

(c)

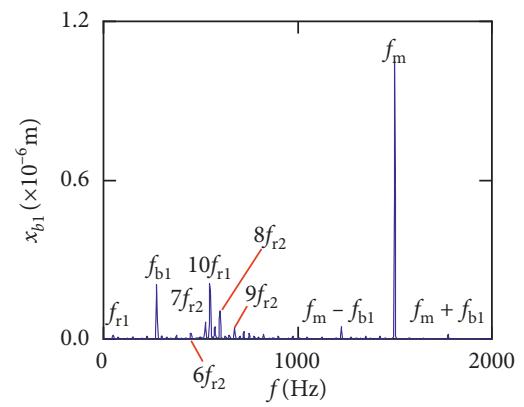

(f)

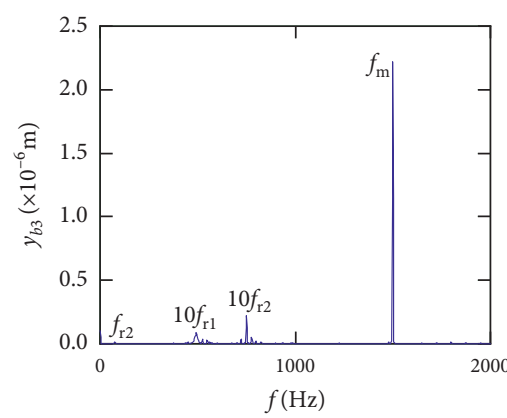

(i)

Figure 15: Frequency of the gear with crack $10 \%$ in (a) $y_{1}$, (b) $\theta_{1}$, (c) $\theta_{1}$, (d) $x_{2}$, (e) $x_{2}$, (f) $x_{b 1}$, (g) $y_{b 1}$, (h) $x_{b 3}$, and (i) $y_{b 3}$ directions.

Figures 12(d), 12(e), 13(d), and 13(e). But the amplitudes of vibration are less changed.

Figures (14)-(16) display, respectively, the frequency spectra of the healthy gear system, gear system with crack $10 \%$, and gear system with crack $30 \%$. The vibration frequency on the healthy gear system is explained in Figures 14(a)-14(i). In the healthy frequency spectra, it is obviously shown that the rotating frequency $f_{\mathrm{r} 1}\left(f_{\mathrm{r} 1}=n_{1} /\right.$ $60=50 \mathrm{~Hz})$ and the mesh frequency $f_{\mathrm{m}}\left(f_{\mathrm{m}}=n_{1} z_{1} /\right.$ $60=1500 \mathrm{~Hz}$ ) are presented in Figure 14. However, besides 


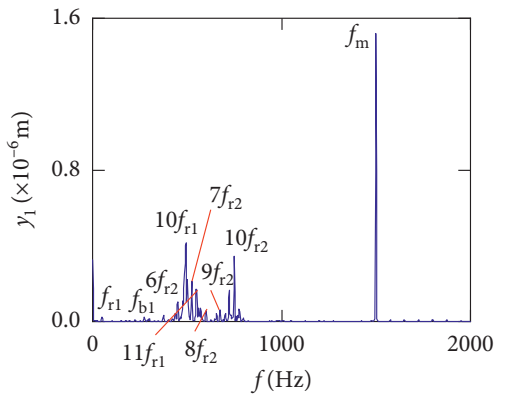

(a)

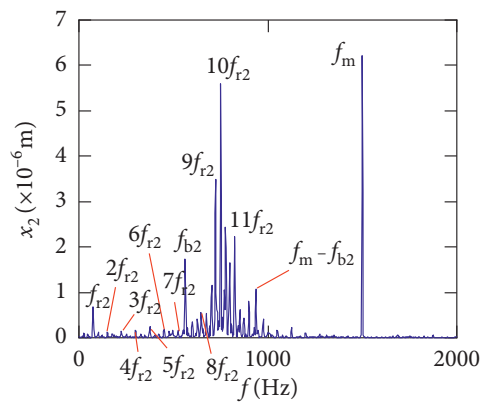

(d)

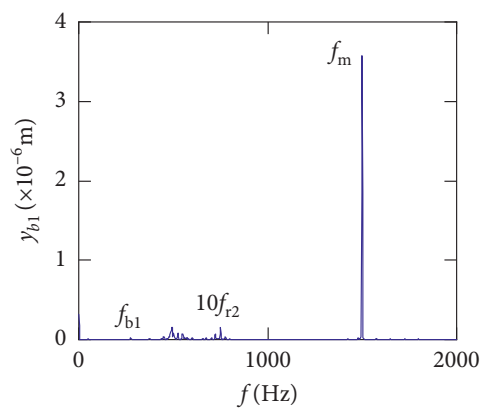

(g)

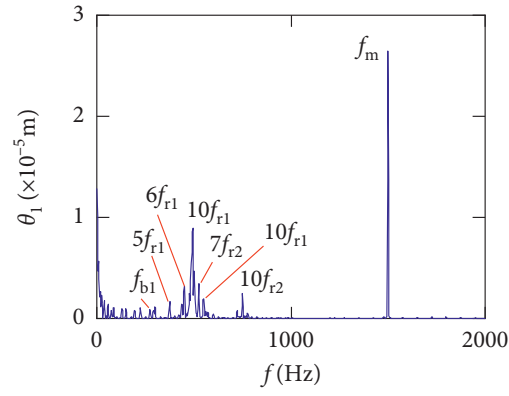

(b)

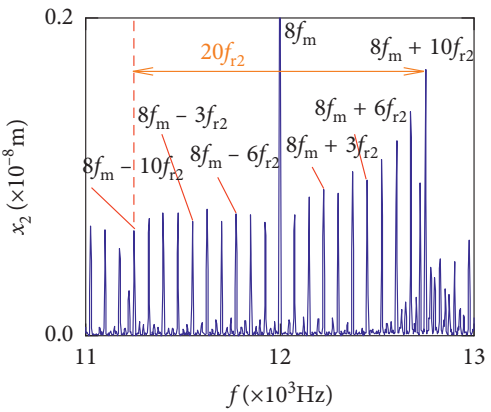

(e)

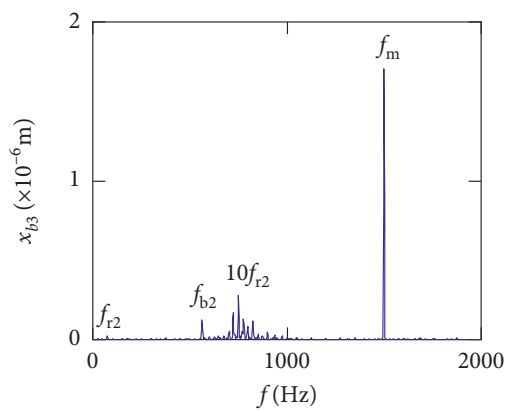

(h)

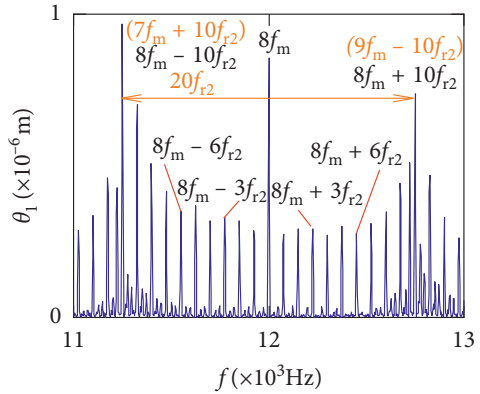

(c)

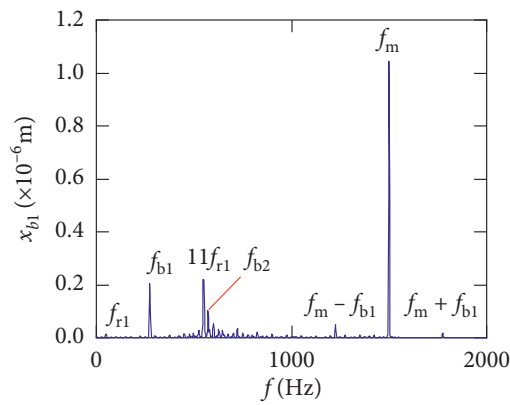

(f)

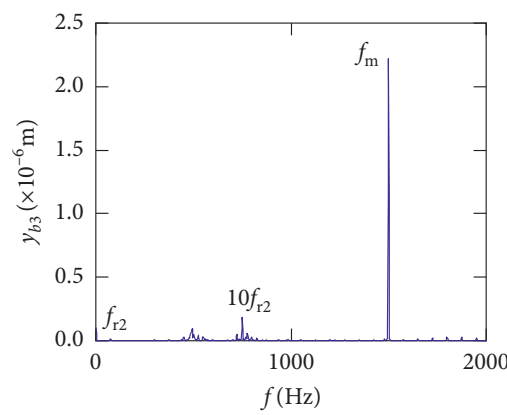

(i)

FIGURE 16: Frequency of the gear with crack $30 \%$ in (a) $y_{1}$, (b) $\theta_{1}$, (c) $\theta_{1}$, (d) $x_{2}$, (e) $x_{2}$, (f) $x_{b 1}$, (g) $y_{b 1}$, (h) $x_{b 3}$, and (i) $y_{b 3}$ directions.

TABle 3: Amplitude of the sideband in $\theta_{1}$ direction.

\begin{tabular}{lcccccccc}
\hline $\begin{array}{l}\text { Crack } \\
\text { depth }(\%)\end{array}$ & $\begin{array}{c}8 f_{\mathrm{m}}-6 f_{\mathrm{r} 2} \\
(\mathrm{~Hz})\end{array}$ & $\begin{array}{c}\text { Amplitude } \\
\left(\times 10^{-6} \mathrm{~m}\right)\end{array}$ & $\begin{array}{c}8 f_{\mathrm{m}}-3 f_{\mathrm{r} 2} \\
(\mathrm{~Hz})^{(\mathrm{a})}\end{array}$ & $\begin{array}{c}\text { Amplitude } \\
\left(\times 10^{-6} \mathrm{~m}\right)\end{array}$ & $\begin{array}{c}8 f_{\mathrm{m}}+3 f_{\mathrm{r} 2} \\
(\mathrm{~Hz})^{(\mathrm{a})}\end{array}$ & $\begin{array}{c}\text { Amplitude } \\
\left(\times 10^{-6} \mathrm{~m}\right)\end{array}$ & $\begin{array}{c}8 f_{\mathrm{m}}+6 f_{\mathrm{r} 2} \\
(\mathrm{~Hz})^{\mathrm{a}}\end{array}$ & $\begin{array}{c}\text { Amplitude } \\
\left(\times 10^{-6} \mathrm{~m}\right)\end{array}$ \\
\hline 0 & 11550 & $\approx 0$ & 11775 & $\approx 0$ & 12225 & $\approx 0$ & 12450 & $\approx 0$ \\
10 & & 0.0913 & $172.0 \%$ & 0.1103 & & $159.6 \%$ & 0.1489 & $130.0 \%$ \\
20 & $230.4 \%$ & 0.3017 & $10.0 \%$ & 0.3009 & $-24.5 \%$ & 0.3866 & $-43.3 \%$ \\
30 & $16.2 \%$ & 0.3503 & & 0.3309 & 0.1741 \\
\hline
\end{tabular}

${ }^{a}$ The first line is the frequency of sideband, respectively, and the other lines indicate the growth rate when every crack $10 \%$ increases.

TABLE 4: Amplitude of the sideband in $x_{2}$ direction.

\begin{tabular}{lcccccccc}
\hline $\begin{array}{l}\text { Crack } \\
\text { depth }(\%)\end{array}$ & $\begin{array}{c}8 f_{\mathrm{m}}-6 f_{\mathrm{r} 2} \\
(\mathrm{~Hz})\end{array}$ & $\begin{array}{c}\text { Amplitude } \\
\left(\times 10^{-8} \mathrm{~m}\right)\end{array}$ & $\begin{array}{c}8 f_{\mathrm{m}}-3 f_{\mathrm{r} 2} \\
(\mathrm{~Hz})^{(\mathrm{a})}\end{array}$ & $\begin{array}{c}\text { Amplitude } \\
\left(\times 10^{-8} \mathrm{~m}\right)\end{array}$ & $\begin{array}{c}8 f_{\mathrm{m}}+3 f_{\mathrm{r} 2} \\
(\mathrm{~Hz})^{(\mathrm{a})}\end{array}$ & $\begin{array}{c}\text { Amplitude } \\
\left(\times 10^{-8} \mathrm{~m}\right)\end{array}$ & $\begin{array}{c}8 f_{\mathrm{m}}+3 f_{\mathrm{r} 2} \\
(\mathrm{~Hz})^{\mathrm{a}}\end{array}$ & $\begin{array}{c}\text { Amplitude } \\
\left(\times 10^{-8} \mathrm{~m}\right)\end{array}$ \\
\hline 0 & 11550 & $\approx 0$ & 11775 & $\approx 0$ & 12225 & $\approx 0$ & 12450 & $\approx 0$ \\
10 & & 0.0183 & $132.4 \%$ & 0.0238 & & $189.7 \%$ & 0.0292 & $192.7 \%$ \\
20 & $192.9 \%$ & 0.0536 & $38.7 \%$ & 0.0553 & $9.0 \%$ & 0.0846 & -6.0358 \\
30 & $34.3 \%$ & 0.0720 & & 0.0767 & 0.0922 & 0.1048 \\
\hline
\end{tabular}

${ }^{a}$ The first line is the frequency of sideband, respectively, and the other lines indicate the growth rate when every crack $10 \%$ increases. 


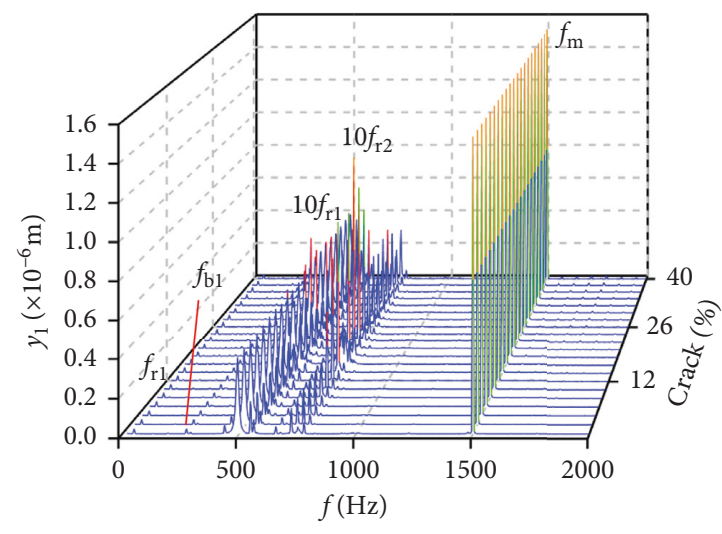

(a)

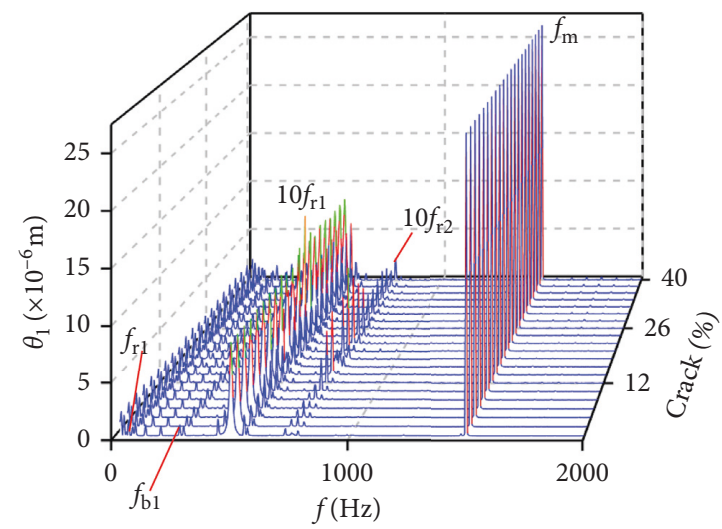

(c)

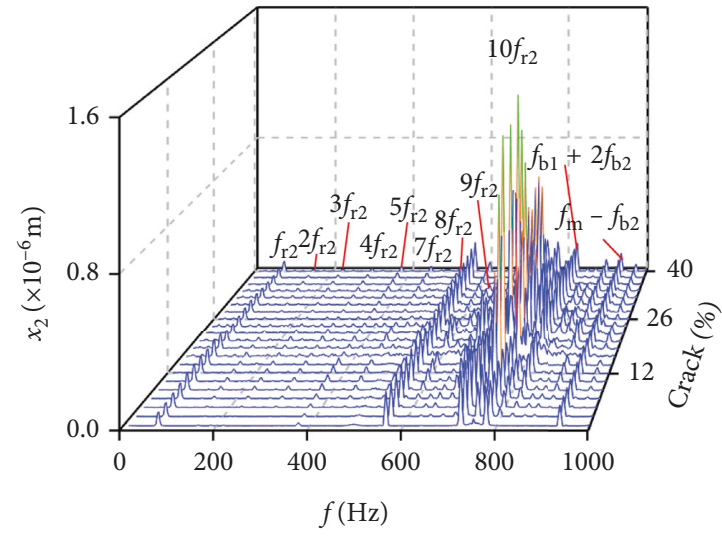

(e)

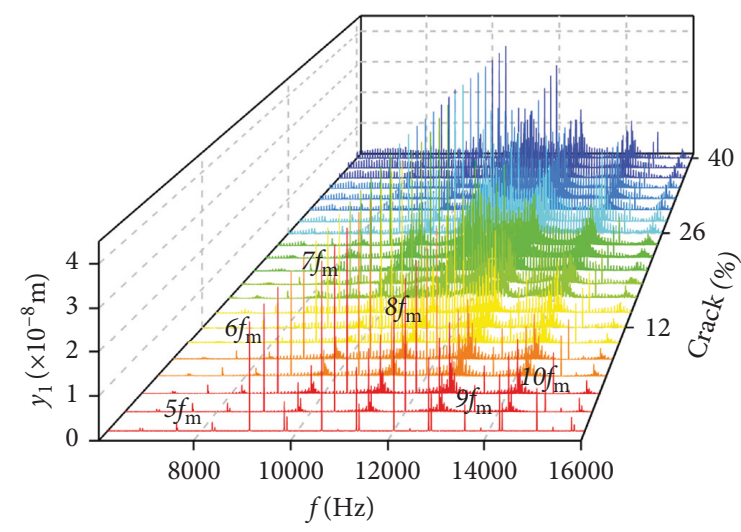

(b)

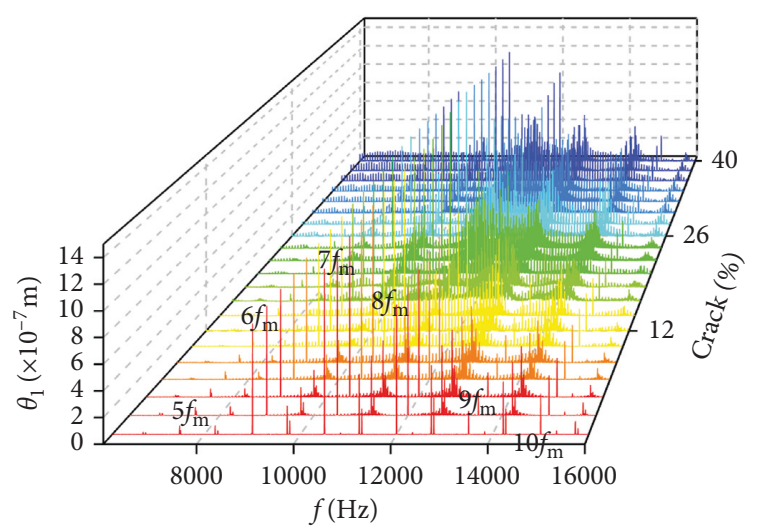

(d)

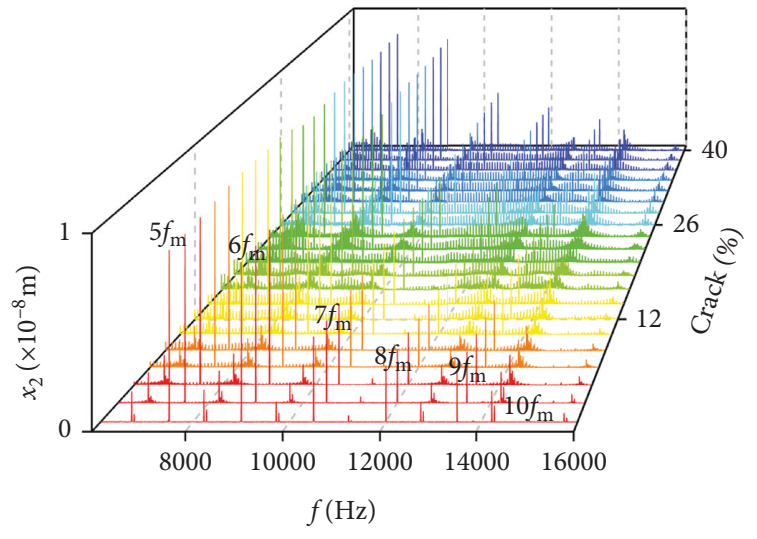

(f)

Figure 17: The waterfall maps in (a) $y_{1}$, (b) $y_{1}$, (c) $\theta_{1}$, (d) $\theta_{1}$, (e) $x_{2}$, and (f) $x_{2}$ directions.

$f_{\mathrm{r} 1}$ and $f_{\mathrm{m}}$, the rotating frequency $f_{\mathrm{r} 2}\left(f_{\mathrm{r} 2}=n_{2} / 60=75 \mathrm{~Hz}\right)$, variable stiffness frequencies $f_{\mathrm{b} 1}\left(f_{\mathrm{b} 1}=N_{1} r_{1} n_{1} / 60\left(R_{1}+r_{1}\right)=\right.$ $274.3 \mathrm{~Hz})$ and $f_{\mathrm{b} 2}\left(f_{\mathrm{b} 1}=N_{2} r_{2} n_{2} / 60\left(R_{2}+r_{2}\right)=563.4 \mathrm{~Hz}\right)$, and combination frequency $0.5 f_{\mathrm{m}}\left(10 f_{\mathrm{r} 2}\right), 2 f_{\mathrm{m}}, 3 f_{\mathrm{m}}, f_{\mathrm{m}}-f_{\mathrm{b} 1}$, $f_{\mathrm{m}}+f_{\mathrm{b} 1}$, and $f_{\mathrm{m}}-f_{\mathrm{b} 2}$ can be observed in the frequency spectra.

The meshing frequency $f_{\mathrm{m}}$ is the highest amplitude and the $\left(0.5 f_{\mathrm{m}}\right) 10 f_{\mathrm{r} 1}$ is the second highest in $y_{1}$ and $\theta_{1}$ direction, as is shown in Figures 14(a) and 14(b). Besides, multiplication frequency of meshing frequency $f_{\mathrm{m}}$ can be seen in Figures $14(\mathrm{~d})$ and $14(\mathrm{e})$, including $2 f_{\mathrm{m}}, 3 f_{\mathrm{m}}, 4 f_{\mathrm{m}}, 5 f_{\mathrm{m}}, 6 f_{\mathrm{m}}$, $7 f_{\mathrm{m}}, 8 f_{\mathrm{m}}, 9 f_{\mathrm{m}}, 10 f_{\mathrm{m}}$, and $11 f_{\mathrm{m}}$. In order to further explore the bearing vibration frequency, Figures 14(f)-14(i) are presented. It is clearly observed that $f_{\mathrm{m}}$ are the highest amplitude frequency. But the frequency components of the transverse $\left(x_{b 1}, x_{b 3}\right)$ are more abundant than longitudinal $\left(y_{b 1}, y_{b 3}\right)$.

For crack $10 \%$, the sidebands near multiplication frequency components can be found in Figures 15(b) and $15(\mathrm{~d})$. The range of the whole sideband of $8 f_{\mathrm{m}}$ is $20 f_{\mathrm{r} 2}$. In addition, it is a significant phenomenon for the early cracked gear system that obvious multiplication frequency of $f_{\mathrm{r} 2}$ $(75 \mathrm{~Hz})$ is observed in Figures 15(f)-15(i). This phenomenon is not found from the healthy gear system. In bearing frequency spectra, sidebands in $x_{b 1}$ and $x_{b 3}$ directions are 


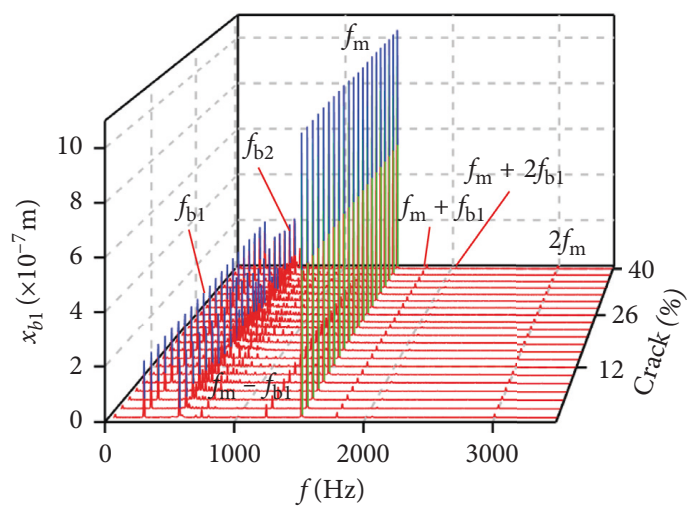

(a)

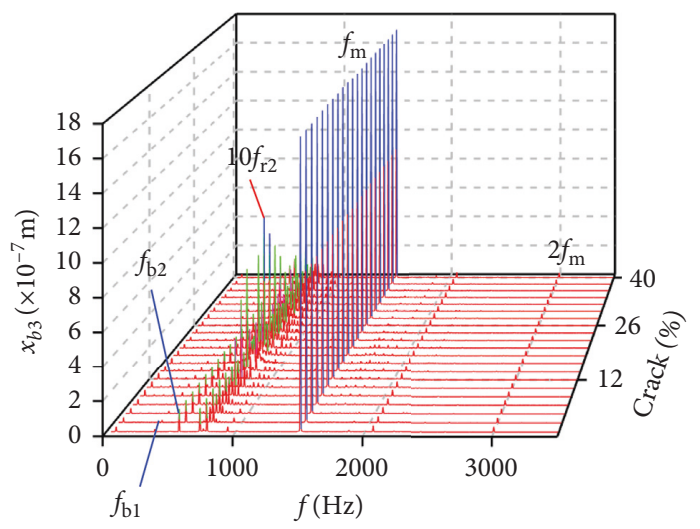

(c)

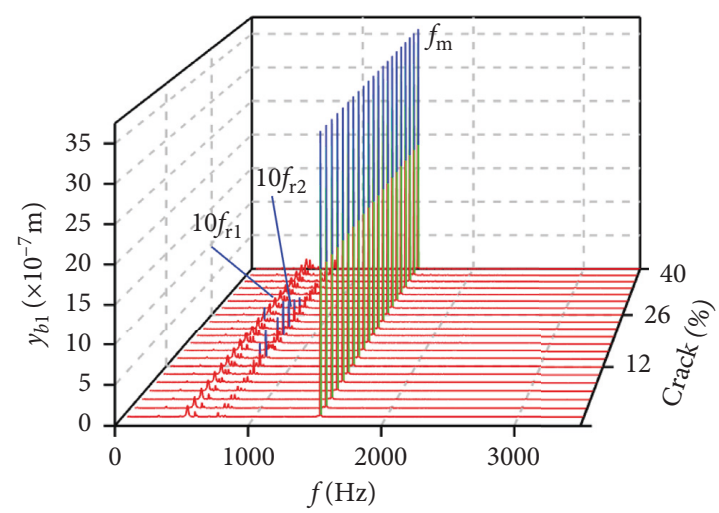

(b)

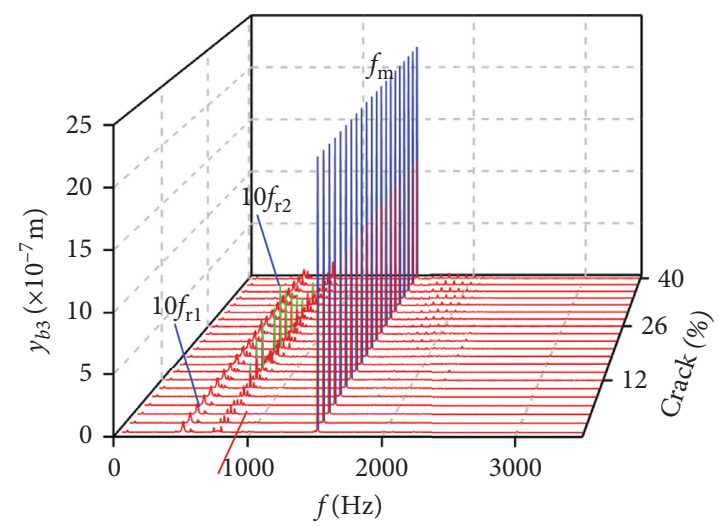

(d)

FIGURE 18: The waterfall maps in (a) $x_{b 1}$, (b) $y_{b 1}$, (c) $x_{b 3}$, (d) $y_{b 3}$ directions.

more obvious than in $y_{b 1}$ and $y_{b 3}$ directions. In addition, $0.5 f_{\mathrm{m}}\left(10 f_{\mathrm{r} 2}\right)$ amplitude increases in all directions.

As the crack depth increases, the changes in the amplitudes of meshing frequency and the multiplication frequency are not obvious. But sidebands of the multiplication frequency of $f_{\mathrm{m}}$ are distinctly changed by the crack. In Figures 15(c), 15(e), 16(c), and 16(e), the amplitude of the sideband gradually increases with the increase in crack depth. For crack 30\%, the frequency component becomes more complex than early crack $(10 \%)$ and healthy system. $0.5 f_{\mathrm{m}}\left(10 f_{\mathrm{r} 2}\right)$ and $f_{\mathrm{m}}$ are the dominant frequencies in all directions.

The statistics data of the sidebands are shown in Tables 3 and 4. In Tables 3 and 4, the amplitudes of sideband sharply increase when the crack depth changes from $10 \%$ to $20 \%$. From $20 \%$ to $30 \%$, the variations will become a slow increase or decrease.

In order to further research the influences of a tooth root crack, waterfall maps of different crack depths in all directions can be seen in Figure 17. The amplitude of $0.5 f_{\mathrm{m}}\left(10 f_{\mathrm{r} 2}\right)$ in $y_{1}$ direction increases in the range of $(0 \%$, $22 \%$ ) in Figure $17(\mathrm{a})$. When the crack depth is $22 \%$, the amplitude of $0.5 f_{\mathrm{m}}\left(10 f_{\mathrm{r} 2}\right)$ is the biggest. Then the amplitude decreases in the range of $(24 \%, 40 \%)$. The amplitude of $10 f_{\mathrm{r} 1}$ only appears a slight fluctuation near crack $22 \%$. The amplitude of $f_{\mathrm{m}}$ shows less variation. In Figure 17(b), the multiplication frequency of $f_{\mathrm{m}}$ is shown, including $5 f_{\mathrm{m}}, 6 f_{\mathrm{m}}, \ldots$,
$10 f_{\mathrm{m}}$. The sidebands appear near multiplication frequency. These sidebands are irregular, and the amplitude of sidebands is different. The change rules of $0.5 f_{\mathrm{m}}\left(10 f_{\mathrm{r} 2}\right), f_{\mathrm{m}}$, and $10 f_{\mathrm{r} 1}$ in $\theta_{1}$ direction are similar to those in $y_{1}$ direction, as is shown in Figure 17(c). In addition, some noise frequency occurs in the lower frequency. In $x_{2}$ direction, $f_{\mathrm{r} 2}$ and its multiplication frequency $2 f_{\mathrm{r} 2}, 3 f_{\mathrm{r} 2}, \ldots, 10 f_{\mathrm{r} 2}$ appear and some compound frequencies $f_{\mathrm{b} 1}+f_{\mathrm{b} 2}, f_{\mathrm{m}}-f_{\mathrm{b} 2}$ also exist in Figure $17(\mathrm{e})$. The multiplication frequency of $f_{\mathrm{m}}$ in $x_{2}$ direction is different from that in $y_{1}$ and $\theta_{1}$ directions (compare Figure $17(\mathrm{f})$ with Figures 17(b) and 17(d)). The amplitude of sidebands increases with crack growing in all directions, as is shown in Figures 17(b), 17(d), and 17(f).

Influences of crack growing on the bearing is shown in Figures 18(a)-18(d). It can be seen that the frequency changes of transverse $\left(x_{b 1}, x_{b 3}\right)$ vibrations are more violent than those of the longitudinal $\left(y_{b 1}, y_{b 3}\right)$ vibrations. $f_{b 1}, f_{b 2}$, $0.5 f_{\mathrm{m}}$, and $f_{\mathrm{m}}$ are found from the bearings in $x_{b 3}$ direction, and the amplitude of $0.5 f_{\mathrm{m}}\left(10 f_{\mathrm{r} 2}\right)$ is changed as the crack depth increases, as is shown in Figure 18(a). The number of noise frequencies in the spectra of transverse vibration is more than that in the frequency spectra of longitudinal vibration.

In Figures 18(b) and 18(d), the frequency components include $0.5 f_{\mathrm{m}}\left(10 f_{\mathrm{r} 2}\right), 10 f_{\mathrm{r} 1}$, and $f_{\mathrm{m}}$.

For the comprehensive comparison, the impact in the transverse vibration is more dramatic than that in the 
longitudinal vibration from the change of the crack, whether the bearings or the gears. Moreover, besides the sidebands, $0.5 f_{\mathrm{m}}\left(10 f_{\mathrm{r} 2}\right)$ and the noise frequency, the amplitude variation of other frequency components is inconspicuous, as shown in Figure 18.

\section{Conclusion}

A nonlinear model with the crack fault, compound backlash, and dynamic stiffness has been built to investigate the coupled lateral-torsional fault features of the 16-DOF gear-rotorbearing system. The potential energy method is employed for analyzing effective meshing stiffness, and assumed that the dynamic backlash is time varying. This time-varying backlash is composed of two parts. One is the dynamic backlash with fractal characteristics based on the microstructure of the tooth surface. The other is time-varying center distance based on the gear vibration characteristics. The comparison between the healthy gear system and crack fault system, including timedomain waveforms and frequency-domain responses, is analyzed in detail. The analysis results are shown as follows:

(1) The effect of crack growing on meshing force of the gear system is distinct at high rotational speed. With the increase in crack, different crack degrees show different vibration responses. In addition, for high speed, the meshing force slowly increases in the range of crack $(0,30 \%)$. But the meshing force rapidly increases within the limits of $30 \%$ and $40 \%$ when the rotational speeds are $600 \mathrm{r} / \mathrm{min}$ and $3000 \mathrm{r} /$ $\mathrm{min}$. The meshing force declines in the range of $30 \%$ and $40 \%$ when the speed is $1800 \mathrm{r} / \mathrm{min}$. The comprehensive elastic deformation $\delta(t)$ and the variation of center distance $\Delta a$ are mainly affected by rotational speed. In addition, $\delta(t)$ and $\Delta a$ slowly increase with growing crack depth. Moreover, the dynamic backlash RMS exhibits peak at crack $22 \%$ when the speed is $3000 \mathrm{r} / \mathrm{min}$. The backlash is a main reason causing the amplitude variation of $0.5 f_{m}\left(10 f_{\mathrm{r} 1}\right)$.

(2) The shaft frequency and multiplication frequency of the dominant frequency can be found in the frequency domain spectra when the gear system appears crack fault. And the amplitudes of these sidebands and the amplitudes of part multiplication frequency go up with the growing of the crack depth, yet the amplitude of frequency components is not changed. For this spur gear model, the pinion and shaft 2 show more obvious fault characteristics due to which sideband effect and time-domain waveforms are more complex as the crack increases.

\section{Nomenclature}

$A_{x}: \quad$ Area of the tooth cross section at point $x$

$A_{x c}:$ After appearing crack, area of the tooth cross section at point $x$

$b(t): \quad$ Dynamic backlash

$\Delta b(t)$ : Microscopic backlash

$b_{h}(t)$ : Vibration variation backlash $c_{b i j}: \quad i=x, y$, and $j=1-4$, bearing damping in $x$ and $y$ directions

$c_{m}: \quad$ Mesh damping

$c_{s i}: \quad i=1-2$, bending damping

$c_{t i}: \quad i=1-2$, torsion damping

$D$ : Fractal dimension controlling the complexity of the fractal curve

$E$ : Young's modulus

$e(t): \quad$ Static transmission error

$e_{0}$ : Mean error

$e_{r}: \quad$ Amplitude error

$F_{f}: \quad$ Friction

$f_{i}$ : $\quad i=1-N$, contact force of the $i$ th rolling element

$F_{m j}: \quad j=1-2$, dynamic force

$F_{x j}: \quad$ Bearing force in $x$ direction

$F_{y j}$ : Bearing force in $y$ direction

$G$ : $\quad$ Shear modulus

$G_{c}: \quad$ Characteristic scale coefficient

$H$ : Heaviside function

$h_{c}$ : Distance between the root the crack and the central line of the tooth

$h_{x}$ : Distance between the point on the tooth's curve and the tooth's central line

$I_{x}$ : Area moment of inertia of the tooth cross section at point $x$

$I_{x c}$ : After appearing crack, area moment of inertia of the tooth cross section at point $x$

$k_{a}$ : Axial compression stiffness of gear

$k_{b}$ : Bending stiffness of gear

$k_{h}$ : Hertzian contact stiffness of gear

$k_{s}$ : Shear stiffness of gear

$k_{s i}: \quad i=1-2$, bending stiffness of shafts

$k_{t}: \quad$ TVMS

$k_{t i}: \quad i=1-2$, torsion stiffness of shafts

$L: \quad$ Width of tooth

$L_{s}$ : Sampling width

$l_{\mathrm{b} i}$ : $\quad i=1-4$, distances between gear's centers and centers of bearing

$l_{j}: \quad j=1-2$, length of shafts

$\overline{N_{1} M}$ : Friction arm

$\overline{N_{2} M}$ : Friction arm

$r_{b 1}$ : Basic circle of gear

$r_{b 2}$ : Basic circle of pinion

$R_{q}$ : RMS roughness

$T_{f 1}$ : Friction torque

$T_{f 2}$ : Friction torque

$U_{a}: \quad$ Axial compression energy

$U_{b}$ : Bending energy

$U_{s}: \quad$ Shear energy

$v_{b}$ : Velocity of cage

$v_{\mathrm{i}}$ : Contact point velocities between the rolling elements and inner ring

$v_{\mathrm{o}}$ : Contact point velocities between the rolling elements and outer ring

$v_{M 1}$ : Velocity on the meshing point of gear

$v_{M 2}$ : Velocity on the meshing point of pinion

$v_{s}$ : $\quad$ Relative sliding velocity of the meshing point $M$ of the tooth pairs 
$x_{g i}: \quad$ Abscissa of centers of mass

$y_{g i}: \quad$ Ordinate of centers of mass

$\varphi_{i}: \quad i=1,2, d, g$ angle displacement

$\varphi_{i}^{1}: \quad i=1-N$, rotational angle of the $i$ th rolling ball

$\delta(t)$ : Deformation between two gears along meshing direction

$\delta_{x i}$ : $\quad$ Elastic deformations of the shaft in $x$ direction

$\delta_{y i}$ : Elastic deformations of the shaft in $y$ direction

$\delta_{i}^{1}$ : $\quad$ Deformation of the $i$ th rolling ball

$\lambda(v s)$ : Direction coefficient

$\omega_{b}$ : Angular velocity of cage

$\omega_{h}$ : Upper cutoff frequency

$\omega_{i}$ : Angular velocity of the inner ring

$\omega_{0}$ : Angular velocity of the outer ring

$\omega_{k}$ : Lower cutoff frequency

$\omega_{m}$ : Meshing frequency

$\rho_{i}$ : $\quad i=1-2$, eccentricity

$\xi_{m}: \quad$ Meshing damping ratio

$\gamma^{n}$ : $\quad$ Space frequency of flank profile

$\mu$ : $\quad$ Friction coefficient.

\section{Data Availability}

All the data are included within the manuscript, and all parameters are valid. Interested researchers can obtain the numerical solution files by contacting the authors via mail (1274186512@qq.com).

\section{Conflicts of Interest}

No potential conflicts in this paper are declared by the authors about research, relationship, and publication.

\section{Acknowledgments}

This work was funded by the Natural Science Foundation of China (no. 51675350), and Key project of Natural Science Foundation of Science and Technology Department of Liaoning Province (20170540673).

\section{References}

[1] P. D. McFadden, "Examination of a technique for the early detection of failure in gears by signal processing of the time domain average of the meshing vibration," Mechanical Systems and Signal Processing, vol. 1, no. 2, pp. 173-183, 1987.

[2] P. D. Mcfadden, "Low frequency vibration generated by gear tooth impacts," NDT International, vol. 18, no. 5, pp. 279-282, 1985.

[3] A. Belsak and J. Flasker, "Detecting cracks in the tooth root of gears," Engineering Failure Analysis, vol. 14, no. 8, pp. 1466-1475, 2007.

[4] D. C. H. Yang and J. Y. Lin, "Hertzian damping, tooth friction and bending elasticity in gear impact dynamics," Journal of Mechanisms Transmissions and Automation in Design, vol. 109, no. 2, pp. 189-196, 1987.

[5] X. H. Tian, "Dynamic simulation for system response of gearbox including localized gear faults," M.S. thesis, University of Alberta, Edmonton, Canada, 2004.

[6] V. J. Govind, K. Sachin, and K. P. Kumar, "Crack growth modeling in spur gear tooth and its effect on mesh stiffness using extended finite element method," Engineering Failure Analysis, vol. 94, pp. 109-120, 2018.

[7] Z. Chen, J. Zhang, W. Zhai, Y. Wang, and J. Liu, "Improved analytical methods for calculation of gear tooth fillet-foundation stiffness with tooth root crack," Engineering Failure Analysis, vol. 82, pp. 72-81, 2017.

[8] Z. Chen and Y. Shao, "Mesh stiffness calculation of a spur gear pair with tooth profile modification and tooth root crack," Mechanism and Machine Theory, vol. 62, pp. 63-74, 2013.

[9] S. Zhou, G. Song, M. Sun, and Z. Ren, "Nonlinear dynamic response analysis on gear-rotor-bearing transmission system," Journal of Vibration \& Control, vol. 24, no. 9, pp. 1-20, 2016.

[10] Q. Chen, Y. Ma, S. Huang, and H. Zhai, "Research on gears' dynamic performance influenced by gear backlash based on fractal theory," Applied Surface Science, vol. 313, pp. 325-332, 2014.

[11] X. Li, J. Xu, W. Pan et al., "Dynamics of gear transmission system with fractal meshing stiffness on tooth surface," Journal of Harbin Institute of Technology, vol. 51, no. 7, pp. 56-62, 2019.

[12] L. Xiang and N. Gao, "Coupled torsion-bending dynamic analysis of gear-rotor-bearing system with eccentricity fluctuation," Applied Mathematical Modelling, vol. 50, pp. 569584, 2017.

[13] A. Saxena, M. Chouksey, and A. Parey, "Effect of mesh stiffness of healthy and cracked gear tooth on modal and frequency response characteristics of geared rotor system," Mechanism and Machine Theory, vol. 107, pp. 261-273, 2017.

[14] O. D. Mohammed and M. Rantatalo, "Dynamic response and time-frequency analysis for gear tooth crack detection," Mechanical Systems and Signal Processing, vol. 66, pp. 612624, 2015.

[15] M. A. Saeed, S. Sadok, and R. P. Mohammad, "Model-Based analysis of spur gears' dynamic behavior in the presence of multiple cracks," Shock and Vibration, vol. 2018, Article ID 1913289, 20 pages, 2018.

[16] H. Ma, X. Pang, J. Zeng, Q. Wang, and B. Wen, "Effects of gear crack propagation paths on vibration responses of the perforated gear system," Mechanical Systems and Signal Processing, vol. 62-63, pp. 113-128, 2015.

[17] H. Ma, R. Song, X. Pang, and B. Wen, "Coupled model of artificial neural network and grey model for tendency prediction of labor turnover," Mathematical Problems in Engineering, vol. 2014, Article ID 832192, 22 pages, 2014.

[18] Z. Chen, W. Zhai, Y. Shao et al., "Analytical model for mesh stiffness calculation of spur gear pair with non-uniformly distributed tooth root crack," Engineering Failure Analysis, vol. 66, pp. 502-514, 2016.

[19] R. Ma and Y. Chen, "Research on the dynamic mechanism of the gear system with local crack and spalling failure," Engineering Failure Analysis, vol. 26, no. 12, pp. 12-20, 2012.

[20] Z. Hu, J. Tang, J. Zhong, and S. Chen, "Frequency spectrum and vibration analysis of high speed gear-rotor system with tooth root crack considering transmission error excitation," Engineering Failure Analysis, vol. 60, pp. 405-441, 2015.

[21] Z. Chen and Y. Shao, "Dynamic simulation of planetary gear with tooth root crack in ring gear," Engineering Failure Analysis, vol. 31, pp. 8-18, 2013.

[22] J. Liu, L. Zhang, S. Zhao et al., "Dynamic characteristics of wind turbine planetary set with crack in sun gear," Acta Energiae Solaris Sinica, vol. 40, no. 1, pp. 192-198, 2019.

[23] A. Kahraman and R. Singh, "Interactions between timevarying mesh stiffness and clearance non-linearities in a 
geared system," Journal of Sound and Vibration, vol. 146, no. 1, pp. 135-156, 1991.

[24] A. Majumdar and C. L. Tien, "Fractal characterization and simulation of rough surfaces," Wear, vol. 136, no. 2, pp. 313-327, 1990.

[25] S. Wang and K. Komvopoulos, "A fractal theory of the interfacial temperature distribution in the slow sliding regime: Part I-elastic contact and heat transfer analysis," Journal of Tribology, vol. 116, no. 4, pp. 812-822, 1994.

[26] G. Shirong and K. Tonder, "The Fractal behavior and fractal characterization of rough surfaces," Tribology, vol. 17, no. 1, pp. 73-80, 1997.

[27] C. Siyu, T. Jinyuan, L. Caiwang, and W. Qibo, "Nonlinear dynamic characteristics of geared rotor bearing systems with dynamic backlash and friction," Mechanism and Machine Theory, vol. 46, no. 4, pp. 466-478, 2011.

[28] Y. Luo, N. Baddour, and M. Liang, "Effects of gear center distance variation on time varying mesh stiffness of a spur gear pair," Engineering Failure Analysis, vol. 75, pp. 37-53, 2017. 


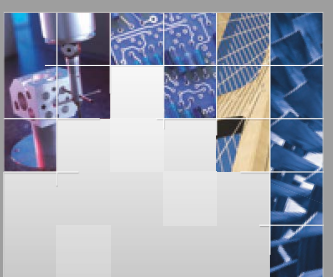

\section{Enfincering}
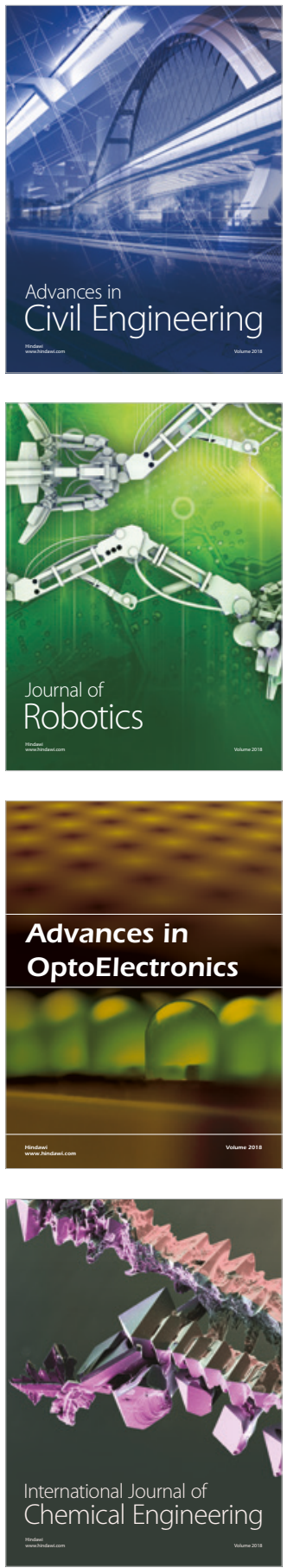

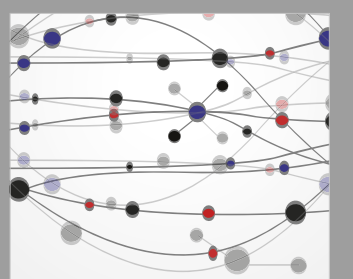

\section{Rotating \\ Machinery}

The Scientific World Journal

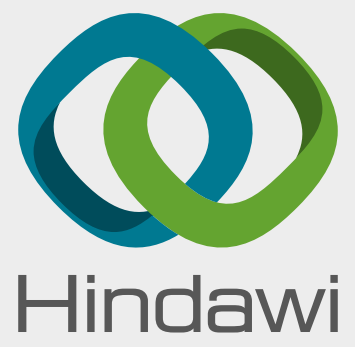

Submit your manuscripts at

www.hindawi.com
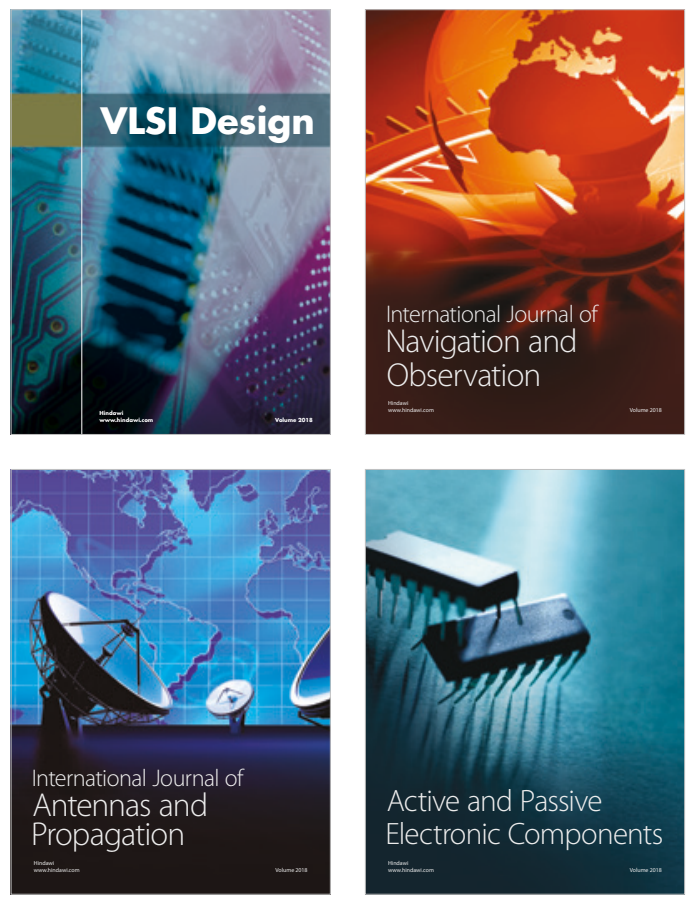
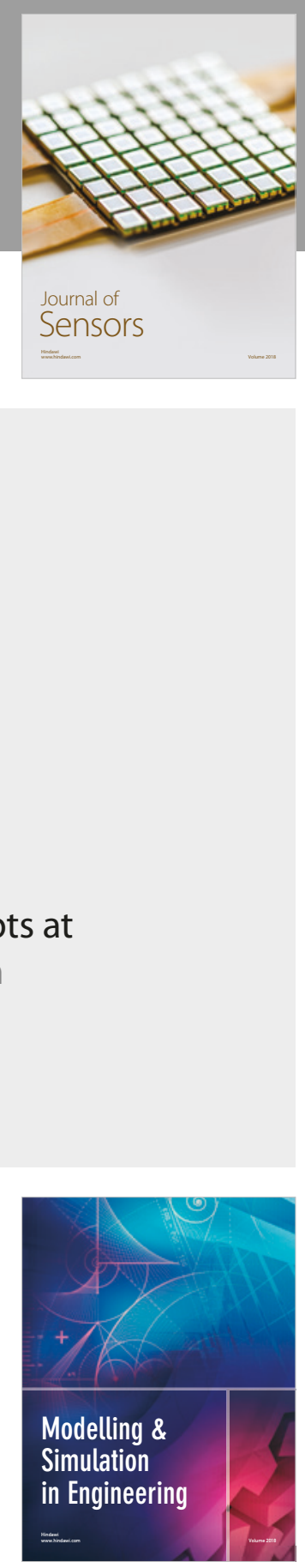

\section{Advances \\ Multimedia}
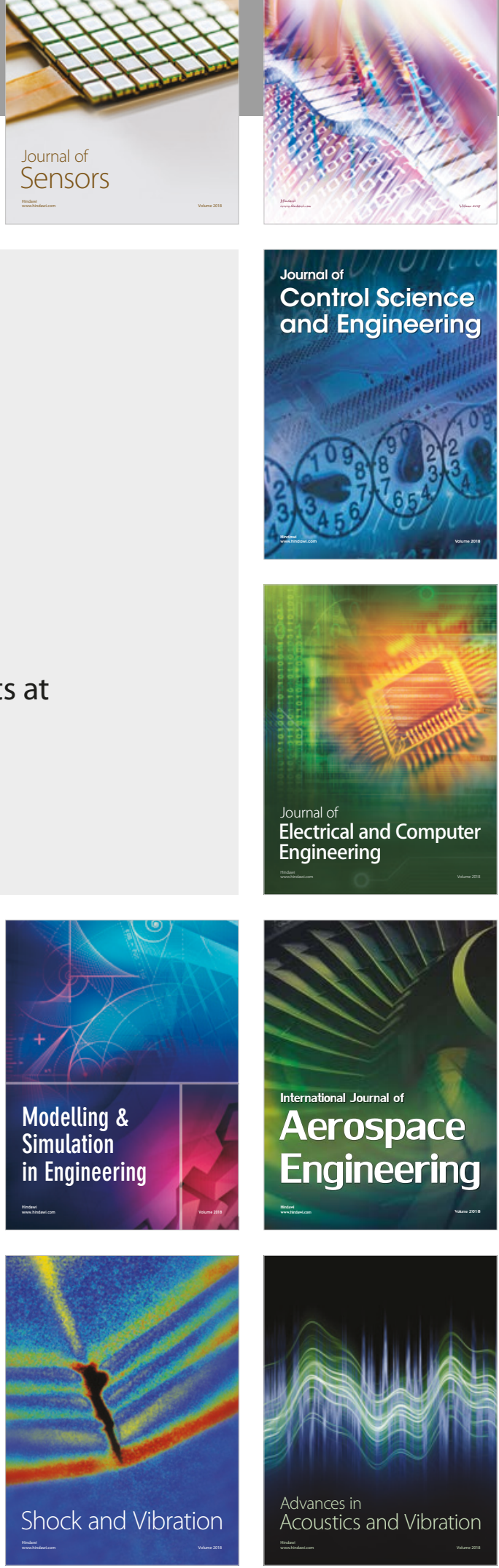